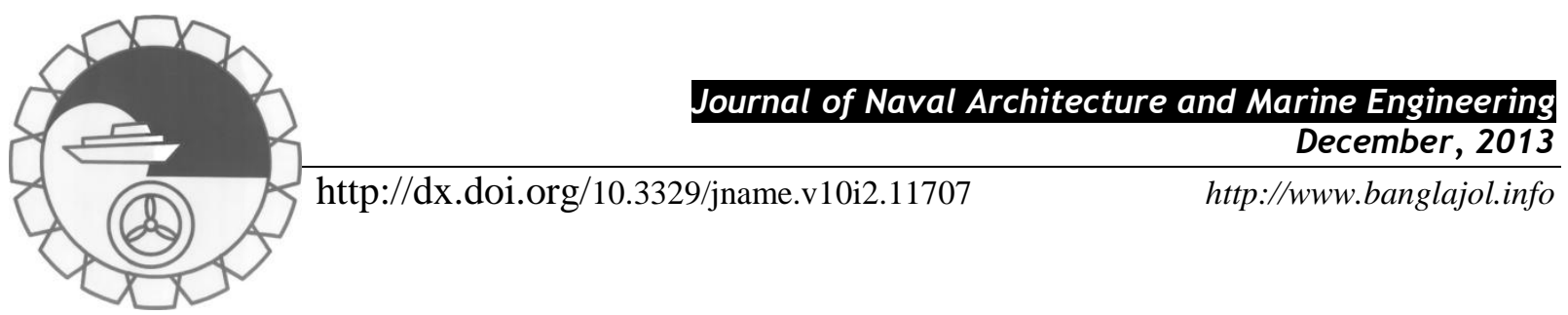

\title{
JOULE HEATING AND MHD FREE CONVECTION FLOW ALONG A VERTICAL WAVY SURFACE WITH VISCOSITY AND THERMAL CONDUCTIVITY DEPENDENT ON TEMPERATURE
}

\author{
Nazma Parveen* and M. A. Alim
}

Department of Mathematics, Bangladesh University of Engineering and Technology, Dhaka-1000, Bangladesh.

*Email: nazma@math.buet.ac.bd

\begin{abstract}
:
A numerical study is conducted to analyze the effect of Joule heating and MHD (magnetohydrodynamic) free convection flow and heat transfer along a uniformly heated vertical wavy surface with temperature dependent variable viscosity and thermal conductivity. The governing boundary layer equations with associated boundary conditions for phenomenon are converted to nondimensional form using the appropriate transformations. The resulting nonlinear system of partial differential equations are mapped into the domain of a vertical flat plate and solved numerically by employing implicit finite difference method, known as the Keller-box scheme. The behavior of the fluid in the ranges of Joule heating parameter (0.0-2.0), viscosity parameter (0.0-20.0) and thermal conductivity parameter $(0.0-10.0)$ are explained in details. It is found that the flow and temperature fields are strongly dependent on the above stated parameters for the ranges considered. The skin friction coefficient and the rate of heat transfer are also presented. The skin friction coefficient for different values of Prandt number $\operatorname{Pr}(=1.0,10.0,25.0,100.0)$ and viscosity variation parameter $\varepsilon(=0.0,1.0,2.0)$ are compared with previously published work and are found to be in excellent agreement.
\end{abstract}

Keywords: Magnetohydrodynamics, Joule heating, temperature dependent viscosity, thermal conductivity, free convection, uniform surface temperature, Keller-box method, wavy surface

\section{NOMENCLATURE}

$C_{f x} \quad$ local skin friction coefficient

$C_{p} \quad$ specific heat at constant pressure $\left(\mathrm{Jkg}^{-1} \mathrm{~K}^{-1}\right)$

$f \quad$ dimensionless stream function

$g \quad$ acceleration due to gravity $\left(\mathrm{ms}^{-2}\right)$

Gr Grashof number

$J \quad$ Joule heating parameter

$k \quad$ thermal conductivity of fluid $\left(\mathrm{Wm}^{-1} \mathrm{~K}^{-1}\right)$

$k_{\infty} \quad$ thermal conductivity of the ambient fluid

$L \quad$ wavelength associated with the wavy surface (m)

M magnetic parameter

$N u_{x} \quad$ local Nusselt number

$P \quad$ pressure of the fluid $\left(\mathrm{Nm}^{-2}\right)$

Pr Prandtl number

$T \quad$ temperature of the fluid in the boundary layer $(\mathrm{K})$

$T_{w} \quad$ temperature at the surface (K)

\section{Greek symbols}

$\alpha$

$\beta$

$\beta_{0}$

$\eta$

$\theta$

$\psi$

$\mu$

$\mu_{\infty}$

$v$

$\rho$

$\sigma_{0}$

$\tau_{w}$

\section{Subscripts}

w wall conditions

$\infty \quad$ ambient conditions 

$T_{\infty} \quad$ temperature of the ambient fluid (K)
$u, v \quad$ dimensionless velocity components along
the $(x, y)$ axes $\left(\mathrm{ms}^{-1}\right)$
$x, y \quad$ axis in the direction along and normal to
the tangent of the surface

\section{Introduction}

The laminar free convection flow of an electrically conducting fluid in the presence of magnetic field and Joule heating is of extraordinary technical importance because of its frequent occurrence in many industrial applications such as geothermal reservoirs, thermal insulations and petroleum reservoirs. When current flows in a wire, the resistance of the wire causes a voltage drop along the wire, as a result electrical energy is lost. This lost electrical energy is converted into thermal energy called Joule heating. It is also necessary to study the heat transfer from an irregular surface because irregular surfaces are often present in many applications. Laminar free convection flow from irregular surfaces can be used for transferring heat in several heat transfer devices; for examples, flat-plate solar collectors, flat-plate condensers in refrigerators, heat exchanger, functional clothing design, geothermal reservoirs and other industrial applications. They are widely used in space heating, refrigeration, air conditioning, power plants, chemical plants, petrochemical plants, petroleum refineries and natural gas processing. Heat exchanger also widely used in industry both for cooling and heating large scale industrial processes. Yao (1983) first investigated the natural convection heat transfer from an isothermal vertical wavy surface and used an extended Prantdl's transposition theorem and a finite-difference scheme. He proposed a simple transformation to study the natural convection heat transfer for an isothermal vertical sinusoidal surface. These simple coordinate transformations method to change the wavy surface into a flat surface. Yao (2006) also studied natural convection along a vertical complex wavy surface. The viscosity of the fluid to be proportional to a linear function of temperature, two semi-empirical formulas was proposed by Charraudeau (1975). Transient free convection flow with temperature dependent viscosity in a fluid saturated porous media has shown by Mehta and Sood (1992) and they found that the flow characteristics substantially change when the effect of temperature dependent viscosity is considered. Hossain (1992) analyzed the viscous and Joule heating effects on MHD free convection flow with variable plate temperature. In his paper, they considered that temperature varied linearly with the distance from the leading edge in the presence of uniformly transverse magnetic field. Rees and Pop (1995) considered the natural convection boundary layer induced by vertical wavy surface exhibiting small amplitude waves embedded in a porous medium. Alam et al. (1997) have studied the problem of free convection from a wavy vertical surface in presence of a transverse magnetic field using Keller box method. They used a sinusoidal surface to elucidate the effects of magnetic field and the amplitude of the wavy surface on the velocity and temperature fields as well as on the local rate of heat transfer. They found that the effect of the magnetic parameter was to decrease the velocity profiles and to increase the temperature profiles and the amplitude of the sinusoidal surface results in decreasing the heat transfer rate. The combined effects of thermal and mass diffusion on the natural convection flow of a viscous incompressible fluid along a vertical wavy surface have investigated by Hossain and Rees (1999). The effect of waviness of the surface on the heat and mass flux is investigated in this paper the combination with the species concentration for a fluid having Prandtl number equal to 0.7. Hossain et al. (2000) investigated the natural convection flow past a permeable wedge for the fluid having temperature dependent viscosity and thermal conductivity. The natural convection heat and mass transfer near a vertical wavy surface with constant wall temperature and concentration in a porous medium have studied by Cheng (2000). He found the effects of the buoyancy ratio, the Lewis number and the dimensionless amplitude of wavy surface on the local Sherwood number and the local Nusselt number. He showed that the amplitudes of the local Nusselt number and the local Sherwood number increase with the amplitude wavelength ratio of the wavy surface. Elbashbeshy (2000) analyzed the free convection flow along a vertical plate, taking into account the variation of the viscosity and thermal diffusivity with temperature in the presence of the magnetic field. The problems of natural convection of fluid with temperature dependent viscosity along a heated vertical wavy surface have studied by Hossain et al. (2002). Molla et al. (2004) have studied numerically natural convection flow along a vertical wavy surface with uniform surface temperature in presence of heat generation/absorption. They found the effect of varying the heat generation/absorption on the heat transfer rate in terms of local Nusselt number as well as on the streamlines and isotherm patterns for very small Prandtl number Pr ranging from 0.001 to 1.0. They concluded that the velocity and temperature distributions for the case of heat generation higher than that of the heat absorption case. Alim et al. (2007) investigated Joule heating effect on the coupling of conduction with MHD free convection flow from a vertical 
flat plate. Combined effects of viscous dissipation and Joule heating on the coupling of conduction and free convection along a vertical flat plate have also studied by Alim et al. (2008). Molla et al. (2009) have also studied natural convection laminar flow with temperature dependent viscosity and thermal conductivity along a vertical wavy surface. Numerical study on a vertical plate with variable viscosity and thermal conductivity has investigated by Palani and Kim (2010). Parveen and Alim (2011) analyzed the effect of Joule heating on magnetohydrodynamic natural convection flow along a vertical wavy surface with viscosity dependent on temperature. Very recently, Parveen and Alim (2012) also considered MHD natural convection flow along a vertical wavy surface in presence of heat generation/absorption with temperature dependent viscosity.

Physical properties like viscosity and thermal conductivity may be changed significantly with temperature. The viscosity of liquids decreases and the viscosity of gases increases with temperature. The viscosity of air is $1.3289 \mathrm{~kg} \mathrm{~m}^{-1} \mathrm{~s}^{-1}, 2.671 \mathrm{~kg} \mathrm{~m}^{-1} \mathrm{~s}^{-1}$ and $3.625 \mathrm{~kg} \mathrm{~m}^{-1} \mathrm{~s}^{-1}$ at $100^{0} \mathrm{C}, 500{ }^{\circ} \mathrm{C}$ and $800^{0} \mathrm{C}$ temperature respectively. The viscosity of water is $1006.523 \mathrm{~kg} \mathrm{~m}^{-1} \mathrm{~s}^{-1}, 471.049 \mathrm{~kg} \mathrm{~m}^{-1} \mathrm{~s}^{-1}, 282.425 \mathrm{~kg} \mathrm{~m}^{-1} \mathrm{~s}^{-1}$ and $138.681 \mathrm{~kg} \mathrm{~m}^{-1} \mathrm{~s}^{-1}$ at $20^{0} \mathrm{C}$, $60^{\circ} \mathrm{C}, 100^{\circ} \mathrm{C}$ and $200^{\circ} \mathrm{C}$ temperature respectively (Cebeci and Bradshow, 1984)). For a liquid, it has been found that the thermal conductivity $k$ varies with temperature in an approximately linear manner in the range from 0 to $400^{\circ} \mathrm{F}$ (Kays, 1966). To predict accurately the flow behavior, it is necessary to take into account viscosity and thermal conductivity.

From the above literature survey, it is found that the effect of Joule heating and MHD free convection heat transfer in Newtonian fluid along a vertical wavy surface in laminar boundary layer flow with temperature dependent variable viscosity and thermal conductivity has not been studied so far. The objective of the present study is to examine numerically the effect of Joule heating and MHD free convection heat transfer with temperature dependent variable viscosity and thermal conductivity by using Prandtl's transposition. The numerical results, including the developments of local skin friction coefficient, local Nusselt number, the velocity and the temperature profiles, the streamlines and the isotherms are presented. The influence of $J$ on the local skin friction coefficient and local Nusselt number are also displayed tabular form in this study.

\section{Formulation of the Problem}

In the present problem, it is considered that the flow is steady, two-dimensional, laminar and incompressible. The gravitational force acts in the vertically downward direction. The boundary layer analysis outlined below allows $\bar{\sigma}(\bar{x})$ being arbitrary, but our detailed numerical work assumed that the surface exhibits sinusoidal deformations. The wavy surface may be described by

$$
\bar{y}_{w}=\bar{\sigma}(\bar{x})=\alpha \sin \left(\frac{n \pi \bar{x}}{L}\right)
$$

where $L$ is the wavelength associated with the wavy surface.

The geometry of the wavy surface and the two-dimensional Cartesian coordinate system are shown in Fig. 1.

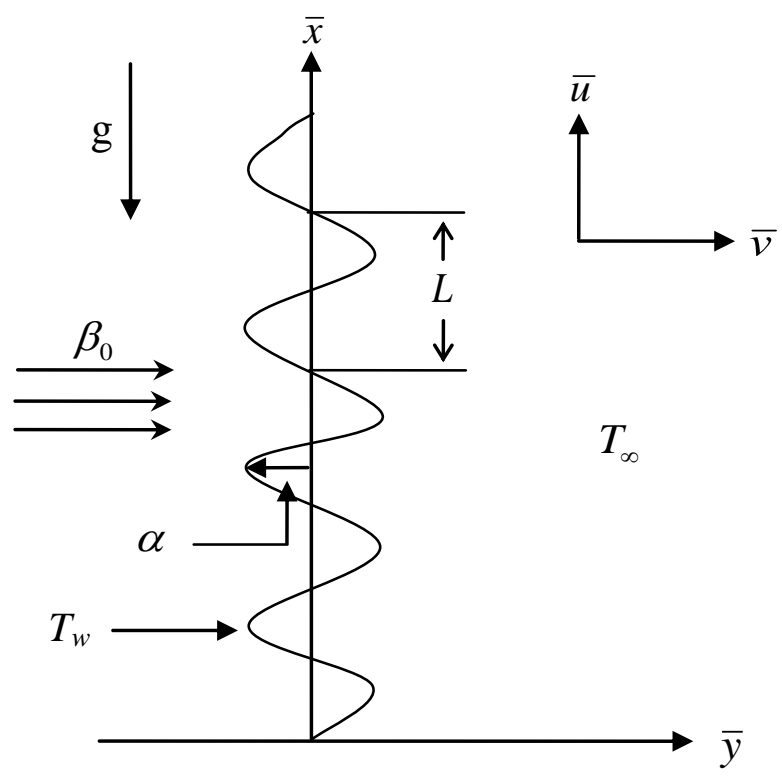

Fig. 1: The coordinate system and the physical model 
Under the usual Boussinesq approximation the governing equations describing the flow are as follows:

$$
\begin{aligned}
& \frac{\partial \bar{u}}{\partial \bar{x}}+\frac{\partial \bar{v}}{\partial \bar{y}}=0 \\
& \bar{u} \frac{\partial \bar{u}}{\partial \bar{x}}+\bar{v} \frac{\partial \bar{u}}{\partial \bar{y}}=-\frac{1}{\rho} \frac{\partial \bar{p}}{\partial \bar{x}}+\frac{1}{\rho} \nabla \cdot(\mu \nabla \bar{u})+g \beta\left(T-T_{\infty}\right)-\frac{\sigma_{0} \beta_{0}^{2}}{\rho} \bar{u} \\
& \bar{u} \frac{\partial \bar{v}}{\partial \bar{x}}+\bar{v} \frac{\partial \bar{v}}{\partial \bar{y}}=-\frac{1}{\rho} \frac{\partial \bar{p}}{\partial \bar{y}}+\frac{1}{\rho} \nabla \cdot(\mu \nabla \bar{v}) \\
& \bar{u} \frac{\partial T}{\partial \bar{x}}+\bar{v} \frac{\partial T}{\partial \bar{y}}=\frac{1}{\rho C_{p}} \nabla \cdot(k \nabla T)+\frac{\sigma_{0} \beta_{0}^{2}}{\rho C_{p}} \bar{u}^{2}
\end{aligned}
$$

where $(\bar{x}, \bar{y})$ are the dimensional coordinates along and normal to the tangent of the surface and $(\bar{u}, \bar{v})$ are the velocity components parallel to $(\bar{x}, \bar{y}), \nabla^{2}\left(=\partial^{2} / \partial x^{2}+\partial^{2} / \partial y^{2}\right)$ is the Laplacian operator, $g$ is the acceleration due to gravity, $\bar{p}$ is the dimensional pressure of the fluid, $\rho$ is the density, $\beta_{0}$ is the strength of magnetic field, $\sigma_{0}$ is the electrical conduction, $\beta$ is the coefficient of thermal expansion, $C_{p}$ is the specific heat due to constant pressure, $\mu(T)$ is the viscosity and $k(T)$ is the thermal conductivity of the fluid in the boundary layer region depending on temperature $T$.

The boundary conditions relevant to the present problem are

$\bar{u}=0, \bar{v}=0, T=T_{w} \quad$ at $\bar{y}=\bar{y}_{w}=\bar{\sigma}(\bar{x})$

$\bar{u}=0, \quad T=T_{\infty}, \quad \bar{p}=p_{\infty} \quad$ as $\quad \bar{y} \rightarrow \infty$

where $T_{w}$ is the surface temperature, $T_{\infty}$ is the ambient temperature of the fluid and $p_{\infty}$ is the pressure of fluid outside the boundary layer.

The variable viscosity and thermal conductivity chosen in this study which was introduced by Charraudeau (1975) and used by Hossain et al. (2002) as follows:

$\mu=\mu_{\infty}\left[1+\varepsilon^{*}\left(T-T_{\infty}\right)\right]$
$k=k_{\infty}\left[1+\gamma^{*}\left(T-T_{\infty}\right)\right]$

where $\mu_{\infty}$ is the viscosity and $k_{\infty}$ is the thermal conductivity of the ambient fluid, $\varepsilon^{*}=\frac{1}{\mu_{f}}\left(\frac{\partial \mu}{\partial T}\right)_{f}$ and $\gamma^{*}=\frac{1}{k_{f}}\left(\frac{\partial k}{\partial T}\right)_{f}$ are constant evaluated at the film temperature of the flow $T_{f}=1 / 2\left(T_{w}+T_{\infty}\right)$.

The following dimensionless variables are introduced for non-dimensionalizing the governing equations which is extended by Yao (1983)

$$
\begin{aligned}
& x=\frac{\bar{x}}{L}, \quad y=\frac{\bar{y}-\bar{\sigma}}{L} G r^{\frac{1}{4}} p=\frac{L^{2}}{\rho v^{2}} G r^{-1} \bar{p} \\
& u=\frac{\rho L}{\mu_{\infty}} G r^{-1 / 2} \bar{u}, \quad v=\frac{\rho L}{\mu_{\infty}} G r^{-1 / 4}\left(\bar{v}-\sigma_{x} \bar{u}\right), \theta=\frac{T-T_{\infty}}{T_{w}-T_{\infty}} \\
& \sigma_{x}=\frac{d \bar{\sigma}}{d \bar{x}}=\frac{d \sigma}{d x}, G r=\frac{g \beta\left(T_{w}-T_{\infty}\right)}{v^{2}} L^{3}
\end{aligned}
$$

where $\theta$ is the dimensionless temperature function and $(u, v)$ are the dimensionless velocity components parallel to $(x, y)$. Here $(x, y)$ are not orthogonal, but a regular rectangular computational grid can be easily fitted in the transformed coordinates. It is also worthwhile to point out that $(u, v)$ are the velocity components parallel to $(x$, $y$ ) which are not parallel to the wavy surface and $v(=\mu / \rho)$ is the kinematic viscosity. 
Introducing the above dimensionless dependent and independent variables into Equations (2)-(5), the following dimensionless form of the governing equations are obtained after ignoring terms of smaller orders of magnitude in $G r$, the Grashof number defined in (9).

$$
\begin{aligned}
& \frac{\partial u}{\partial x}+\frac{\partial v}{\partial y}=0 \\
& u \frac{\partial u}{\partial x}+v \frac{\partial u}{\partial y}=-\frac{\partial p}{\partial x}+G r^{1 / 4} \sigma_{x} \frac{\partial p}{\partial y}+\left(1+\sigma_{x}^{2}\right)(1+\varepsilon \theta) \frac{\partial^{2} u}{\partial y^{2}} \\
& +\varepsilon\left(1+\sigma_{x}^{2}\right) \frac{\partial \theta}{\partial y} \frac{\partial u}{\partial y}-M u+\theta \\
& \sigma_{x}\left(u \frac{\partial u}{\partial x}+v \frac{\partial u}{\partial y}\right)=-G r^{1 / 4} \frac{\partial p}{\partial y}+\sigma_{x}\left(1+\sigma_{x}^{2}\right)(1+\varepsilon \theta) \frac{\partial^{2} u}{\partial y^{2}} \\
& +\varepsilon \sigma\left(1+\sigma_{x}^{2}\right) \frac{\partial \theta}{\partial y} \frac{\partial u}{\partial y}-\sigma_{x x} u^{2} \\
& u \frac{\partial \theta}{\partial x}+v \frac{\partial \theta}{\partial y}=\frac{1}{\operatorname{Pr}}\left(1+\sigma_{x}^{2}\right)(1+\gamma \theta) \frac{\partial^{2} \theta}{\partial y^{2}}+\frac{1}{\operatorname{Pr}}\left(1+\sigma_{x}^{2}\right) \gamma\left(\frac{\partial \theta}{\partial y}\right)^{2}+J u^{2}
\end{aligned}
$$

It is worth noting that the $\sigma_{x}$ and $\sigma_{x x}$ indicate the first and second differentiations of $\sigma$ with respect to $x$, therefore, $\sigma_{x}=d \bar{\sigma} / d X=d \sigma / d x$ and $\sigma_{x x}=d \sigma_{x} / d x$.

In the above equations $\operatorname{Pr}=\frac{C_{p} \mu_{\infty}}{k_{\infty}}$ is the Prandtl number, $M=\frac{\sigma_{0} \beta_{0}^{2} L^{2}}{\mu G r^{1 / 2}}$ is the magnetic parameter, $J=\frac{\sigma_{0} \beta_{0}^{2} v G r^{1 / 2}}{\rho C_{p}\left(T_{w}-T_{\infty}\right)}$ is the Joule heating parameter, $\varepsilon=\varepsilon^{*}\left(T_{w}-T_{\infty}\right)$ is the viscosity variation parameter and $\gamma=\gamma^{*}\left(T_{w}-T_{\infty}\right)$ is the thermal conductivity variation parameter.

It can easily be seen that the convection induced by the wavy surface is described by Equations (10)-(13). We further notice that, Equation (12) indicates that the pressure gradient along the $y$-direction is $O\left(G r^{-1 / 4}\right)$, which implies that lowest order pressure gradient along $x$-direction can be determined from the inviscid flow solution. For the present problem this pressure gradient $(\partial p / \partial x=0)$ is zero. Equation (12) further shows that $G r^{-1 / 4} \partial p / \partial y$ is $O(1)$ and is determined by the left-hand side of this equation. Thus, the elimination of $\partial p / \partial y$ from Equations (11) and (12) leads to

$$
\begin{aligned}
& u \frac{\partial u}{\partial x}+v \frac{\partial u}{\partial y}=\left(1+\sigma_{x}^{2}\right)(1+\varepsilon \theta) \frac{\partial^{2} u}{\partial y^{2}}-\frac{\sigma_{x} \sigma_{x x}}{1+\sigma_{x}^{2}} u^{2}+\varepsilon\left(1+\sigma_{x}^{2}\right) \frac{\partial u}{\partial y} \frac{\partial \theta}{\partial y} \\
& -\frac{M}{1+\sigma_{x}^{2}} u+\frac{1}{1+\sigma_{x}^{2}} \theta
\end{aligned}
$$

The corresponding boundary conditions for the present problem then turn into

$$
\left.\begin{array}{llll}
u & =v=0, \quad \theta=1 \quad \text { at } & y=0 \\
u & =\theta=0, \quad p=0 \quad \text { as } & y \rightarrow \infty
\end{array}\right\}
$$

Now we introduce the following transformations to reduce the governing equations to a convenient form:

$$
\psi=x^{3 / 4} f(x, \eta), \quad \eta=y x^{-1 / 4}, \quad \theta=\theta(x, \eta)
$$


where $\eta$ is the pseudo similarity variable and $\psi$ is the stream function that satisfies the Equation (10) and is defined by

$u=\frac{\partial \psi}{\partial y}, \quad v=-\frac{\partial \psi}{\partial x}$.

Introducing the transformations given in Equation (16) into Equations (14) and (13) the momentum and energy equations respectively transformed into the new co-ordinate system. Thus the resulting equations are obtained

$$
\begin{aligned}
& \left(1+\sigma_{x}^{2}\right)(1+\varepsilon \theta) f^{\prime \prime \prime}+\frac{3}{4} f f^{\prime \prime}-\left(\frac{1}{2}+\frac{x \sigma_{x} \sigma_{x x}}{1+\sigma_{x}^{2}}\right) f^{\prime 2}+\frac{1}{1+\sigma_{x}^{2}} \theta \\
& -\frac{M x^{1 / 2}}{1+\sigma_{x}^{2}} f^{\prime}+\varepsilon\left(1+\sigma_{x}^{2}\right) \theta^{\prime} f^{\prime \prime}=x\left(f^{\prime} \frac{\partial f^{\prime}}{\partial x}-f^{\prime \prime} \frac{\partial f}{\partial x}\right) \\
& \frac{1}{\operatorname{Pr}}\left(1+\sigma_{x}^{2}\right)(1+\gamma \theta) \theta^{\prime \prime}+\frac{1}{\operatorname{Pr}}\left(1+\sigma_{x}^{2}\right) \gamma \theta^{\prime 2}+\frac{3}{4} f \theta^{\prime}+J x^{3 / 2} f^{\prime 2} \\
& =x\left(f^{\prime} \frac{\partial \theta}{\partial x}-\theta^{\prime} \frac{\partial f}{\partial x}\right)
\end{aligned}
$$

The boundary conditions (15) now take the following form:

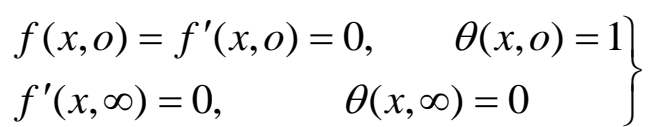

In the above equations prime denote the differentiation with respect to $\eta$.

The quantities of physical interested, namely, the shearing stress $\tau_{\mathrm{w}}$ in terms of the skin friction coefficient $C_{f x}$ and the rate of heat transfer in terms of Nusselt number $N u_{x}$ are prescribed by

$$
C_{f x}=\frac{2 \tau_{w}}{\rho U_{\infty}^{2}} \text { and } N u_{x}=\frac{q_{w} x}{k_{\infty}\left(T_{w}-T_{\infty}\right)}
$$

where $\tau_{w}=(\mu \bar{n} \cdot \nabla \bar{u})_{y=0}$ and $q_{w}=-k(\bar{n} \cdot \nabla T)_{y=0}$

Using the transformations (16) and Equation (22) into Equation (21), the local skin friction coefficient $C_{f x}$ and the rate of heat transfer in terms of the local Nusselt number $N u_{x}$ takes the following form:

$$
\begin{aligned}
& C_{f x}(G r / x)^{1 / 4} / 2=(1+\varepsilon) \sqrt{1+\sigma_{x}^{2}} f^{\prime \prime}(x, o) \\
& N u_{x}(G r / x)^{-1 / 4}=-(1+\gamma) \sqrt{1+\sigma_{x}^{2}} \theta^{\prime}(x, o)
\end{aligned}
$$

\section{Method of Solution}

The transformed boundary layer equations solved numerically using the very efficient implicit finite difference method known as the Keller box scheme developed by Keller (1978), which is well documented by Cebeci and Bradshaw (1984).

To apply the aforementioned method, equations (18) and (19) with their boundary condition (20) are first converted into the following system of first order equations. For this purpose we introduce new dependent variables $u(\xi, \eta), v(\xi, \eta), p(\xi, \eta)$ and $g(\xi, \eta)$ so that the transformed momentum and energy equations can be written as

$$
\begin{aligned}
& f^{\prime}=u \\
& u^{\prime}=v
\end{aligned}
$$




$$
g^{\prime}=p
$$

$P_{1} S v^{\prime}+P_{2} f v-P_{3} u^{2}+P_{4} g-P_{5} u+P_{6} p v=\xi\left(u \frac{\partial u}{\partial \xi}-v \frac{\partial f}{\partial \xi}\right)$

$\frac{1}{\operatorname{Pr}} P_{1} T p^{\prime}+\frac{1}{\operatorname{Pr}} P_{7} p^{2}+P_{2} f p+P_{8} u^{2}=\xi\left(u \frac{\partial g}{\partial \xi}-p \frac{\partial f}{\partial \xi}\right)$

where $x=\xi, \theta=\mathrm{g}$ and

$$
\begin{aligned}
& P_{1}=\left(1+\sigma_{x}^{2}\right), \quad P_{2}=\frac{3}{4}, \quad P_{3}=\frac{1}{2}+\frac{x \sigma_{x} \sigma_{x x}}{1+\sigma_{x}^{2}}, \quad P_{4}=\frac{1}{1+\sigma_{x}^{2}}, \quad P_{5}=\frac{M x^{1 / 2}}{1+\sigma_{x}^{2}}, \\
& P_{6}=\varepsilon\left(1+\sigma_{x}^{2}\right), \quad P_{7}=\left(1+\sigma_{x}^{2}\right) \gamma, P_{8}=J x^{3 / 2}, \mathrm{~S}=(1+\varepsilon \theta) \text { and } \mathrm{T}=(1+\gamma \theta)
\end{aligned}
$$

and the boundary conditions (20) are

$$
\begin{aligned}
& f(\xi, 0)=0, u(\xi, 0)=0, g(\xi, 0)=1 \\
& u(\xi, \infty)=0, g(\xi, \infty)=0
\end{aligned}
$$

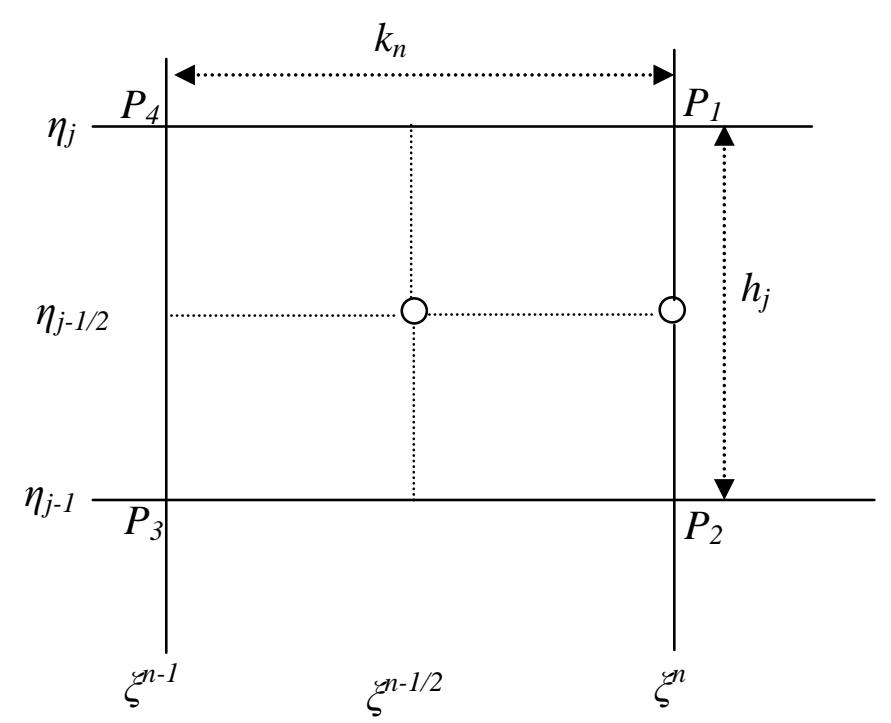

Fig. 2: Net rectangle of difference approximations for the Box scheme.

Now consider the net rectangle on the $(\xi, \eta)$ plane shown in the Fig. 2 and denote the net points by

$$
\begin{aligned}
& \xi^{0}=0, \xi^{n}=\xi^{n-1}+k_{n}, \quad n=1,2, \cdots \cdots \cdots \cdots, N \\
& \eta_{0}=0, \eta_{j}=\eta_{j-1}+h_{j,} \quad j=1,2, \cdots \cdots \cdots \cdots, J
\end{aligned}
$$

Here $n$ and $j$ are just sequence of numbers on the $(\xi, \eta)$ plane, $k_{n}$ and $h_{j}$ are the variable mesh widths. Approximate the quantities $f, u, v$ and $p$ at the points $\left(\xi^{n}, \eta_{j}\right)$ of the net by $f_{j}^{n}, u_{j}^{n}, v_{j}^{n}, p_{j}^{n}$ which call net function. It is also employed that the notation $P_{j}^{n}$ for the quantities midway between net points shown in Fig. 2 and for any net function as

$$
\xi^{n-1 / 2}=\frac{1}{2}\left(\xi^{n}+\xi^{n-1}\right)
$$




$$
\begin{aligned}
& \eta_{j-1 / 2}=\frac{1}{2}\left(\eta_{j}+\eta_{j-1}\right) \\
& g_{j}^{n-1 / 2}=\frac{1}{2}\left(g_{j}^{n}+g_{j}^{n-1}\right) \\
& g_{j-1 / 2}^{n}=\frac{1}{2}\left(g_{j}^{n}+g_{j-1}^{n}\right)
\end{aligned}
$$

The finite difference approximations according to box method to the three first order ordinary differential equations (25) - (27) are written for the mid point $\left(\xi, \eta_{j-1 / 2}\right)$ of the segment $P_{1} P_{2}$ shown in the Fig. 2.

$$
\begin{aligned}
& \frac{f_{j}^{n}-f_{j-1}^{n}}{h_{j}}=u_{j-1 / 2}^{n}=\frac{u_{j-1}^{n}+u_{j}^{n}}{2} \\
& \frac{u_{j}^{n}-u_{j-1}^{n}}{h_{j}}=v_{j-1 / 2}^{n}=\frac{v_{j-1}^{n}+v_{j}^{n}}{2} \\
& \frac{g_{j}^{n}-g_{j-1}^{n}}{h_{j}}=p_{j-1 / 2}^{n}=\frac{p_{j-1}^{n}+p_{j}^{n}}{2}
\end{aligned}
$$

The finite difference approximations to the two first order differential equations (28) and (29) are written for the mid point $\left(\xi^{n-1 / 2}, \eta_{j-1 / 2}\right)$ of the rectangle $P_{1} P_{2} P_{3} P_{4}$. This procedure yields

$$
\begin{aligned}
& \frac{1}{2}\left(P_{1} S\right)_{j-1 / 2}^{n}\left(\frac{v_{j}^{n}-v_{j-1}^{n}}{h_{j}}\right)+\frac{1}{2}\left(P_{1} S\right)_{j-1 / 2}^{n-1}\left(\frac{v_{j}^{n-1}-v_{j-1}^{n-1}}{h_{j}}\right)+\left(P_{2} f v\right)_{j-1 / 2}^{n-1 / 2}-\left(P_{3} u^{2}\right)_{j-1 / 2}^{n-1 / 2} \\
& +\left(P_{4} g\right)_{j-1 / 2}^{n-1 / 2}-\left(P_{5} u\right)_{j-1 / 2}^{n-1 / 2}+\left(P_{6} p v\right)_{j-1 / 2}^{n-1 / 2} \\
& =\xi_{j-1 / 2}^{n-1 / 2}\left(u_{j-1 / 2}^{n-1 / 2} \frac{u_{j-1 / 2}^{n}-u_{j-1 / 2}^{n-1}}{k_{n}}-v_{j-1 / 2}^{n-1 / 2} \frac{f_{j-1 / 2}^{n}-f_{j-1 / 2}^{n-1}}{k_{n}}\right) \\
& \frac{1}{2 \operatorname{Pr}}\left\{\left(P_{1} T\right)_{j-1 / 2}^{n}\right\}\left(\frac{p_{j}^{n}-p_{j-1}^{n}}{h_{j}}\right)+\frac{1}{2 \operatorname{Pr}}\left\{\left(P_{1} T\right)_{j-1 / 2}^{n-1}\right\}\left(\frac{p_{j}^{n-1}-p_{j-1}^{n-1}}{h_{j}}\right)+\left(P_{2} f p\right)_{j-1 / 2}^{n-1 / 2} \\
& +\left(P_{7} p^{2}\right)_{j-1 / 2}^{n-1 / 2}+\left(P_{8} u^{2}\right)_{j-1 / 2}^{n-1 / 2}=\xi_{j-1 / 2}^{n-1 / 2}\left(u_{j-1 / 2}^{n-1 / 2} \frac{g_{j-1 / 2}^{n}-g_{j-1 / 2}^{n-1}}{k_{n}}-p_{j-1 / 2}^{n-1 / 2} \frac{f_{j-1 / 2}^{n}-f_{j-1 / 2}^{n-1}}{k_{n}}\right)
\end{aligned}
$$

The above equations are to be linearized by using Newton's Quasi-linearization method. Then linear algebraic equations can be written in block matrix which form a coefficient matrix. The whole procedure, namely reduction to first order followed by central difference approximations, Newton's Quasi-linearization method and the block Thomas algorithm, is well known as the Keller-box method. In the program test finer axial step sizes is tried and find to give acceptable accuracy. A uniform grid of 201 points is used in $x$ - direction with $\Delta x=$ 0.05 , while a non-uniform grid of 76 points lying between $\eta=0.0$ and 10.017 is chosen. Grid points are concentrated towards the heated surface in order to improve resolution and the accuracy of the computed values of the surface shear stress and rate of heat transfer. During the program test, the convergent criteria for the relative errors between two iterations are less $10^{-5}$. It means that iterative procedure is stopped when the maximum change between successive iterates is less then $10^{-5}$. 


\section{Results and Discussion}

Numerical values of the shear stress in terms of the skin friction coefficients $C_{f x}$ and the rate of heat transfer in terms of the Nusselt number $N u_{x}$ are calculated from equations (23) and (24) for a wide range of the axial distance $x$ starting from the leading edge. The velocity, the temperature, the streamlines as well as the isotherms are also obtained. These are shown graphically in Figs. 3-15 for different values of the viscosity parameter $\varepsilon=$ 0.0 (constant viscosity) to 20.0 and Joule heating parameter $J=0.0$ (without Joule heating) to 2.0, thermal conductivity parameter $\gamma=0.0$ (constant thermal conductivity) to 10.0 and the amplitude-to-length ratio of the wavy surface ranging from $\alpha=0.0$ (flat plate) to 0.4 . The skin friction coefficient $C_{f x}$ and local rate of heat transfer $N u_{x}$ varies according to the slope of the wavy surface. This is due to the alignment of the buoyancy force $1 /\left(1+\sigma_{x}^{2}\right)$, as shown in equation (18), which drives the flow tangentially to the wavy surface.

The local skin friction coefficient and the rate of heat transfer in terms of the local Nusselt number against $x$ for various $J$ while $\alpha=0.3, M=0.02, \gamma=4.0, \varepsilon=5.0$ and $\operatorname{Pr}=0.5$ are displayed in Figs. 3(a)-(b). It is noted that the increasing skin friction coefficient slightly changes against the axial distance of $x$ along the upstream region of the surface. On the other hand, an opposite situation is observed in the case of local rate of heat transfer $N u_{x}$ at different position of $x$. The effect of Joule heating in fluid is very small. Thus the skin friction coefficient increases by only $0.30 \%$ and the rate of heat transfer decreases by $1.73 \%$ when $J$ changes from 0.0 to 0.15 .

The effect of $\varepsilon$ on the surface shear stress in terms of the local skin friction coefficient and the local Nusselt number against $x$ are exposed within the boundary layer with $\alpha=0.3, M=0.8, J=0.02, \gamma=5.0$ and $\operatorname{Pr}=1.0$ in Fig. 4. This figure shows that the skin friction coefficient increases monotonically along the upstream direction of the surface and reduces the heat transfer rate for increasing values of variable viscosity. The decreasing heat transfer rate becomes slower in the downstream region against $x$. The maximum values of local skin friction coefficient are recorded to be 0.94844 and 2.76364 for $\varepsilon=0.0$ and 20.0 respectively which occurs at $x=0.50$. Again the peak values of the rate of heat transfer are 0.85232 for $\varepsilon=0.0$ which occurs at the surface and 0.60373 for $\varepsilon=20.0$ which occurs at $x=0.45$. It is observed that the local skin friction coefficient increases by approximately $65 \%$ and the rate of heat transfer devalues by approximately $29 \%$ as $\varepsilon$ increases from 0.0 to 20.0 .
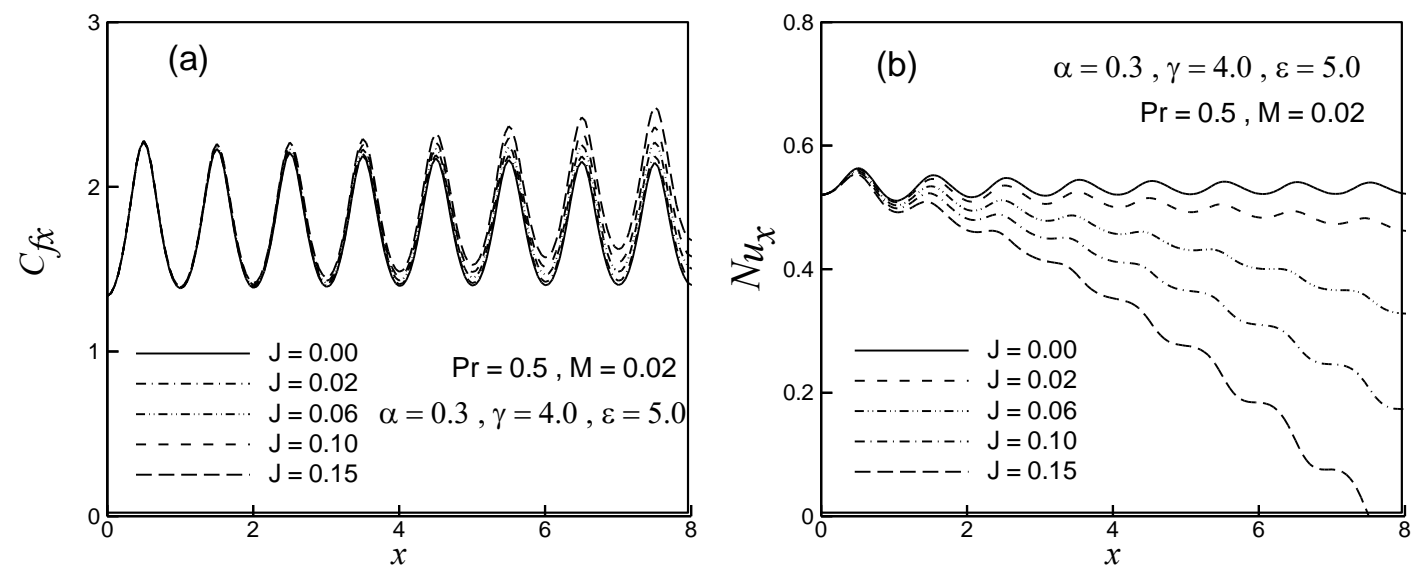

Fig. 3: Effect of $J$ on (a) skin friction coefficient $C_{f x}$ and (b) rate of heat transfer.

The surface shear stress in terms of skin friction coefficient and local rate of heat transfer for influence of temperature dependent thermal conductivity parameter $(\gamma=0.0,2.0,6.0,10.0)$ while Prandtl number $\operatorname{Pr}=0.73, \varepsilon$ $=5.0, J=0.02, \alpha=0.3$ and $M=0.5$ are displayed in Fig. 5. As the value of $\gamma$ increases, the skin friction coefficient and heat transfer coefficient increase significantly along the upstream direction of the surface. The maximum values of the skin friction coefficient are recorded to be 1.54766 and 2.15417 for $\gamma=0.0$ and 10.0 which occurs at $x=0.50$. Again the highest values of heat transfer rate are recorded to be 0.25035 and 0.97869 for $\gamma=0.0$ and 10.0 respectively. That occurs at the different positions of $x$. Thus the skin friction coefficient and the rate of heat transfer coefficient increase by approximately $28 \%$ and $74 \%$ respectively when $\gamma$ changes from 0 to 10.0 .

Figs 6(a) and 6(b) show that increase in the value of the amplitude-to-length ratio of wavy surface $(\alpha=0.0,0.1$, $0.2,0.3,0.4)$ leads to decrease the value of the skin friction coefficient and the rate of heat transfer in terms of the local Nusselt number while $\operatorname{Pr}=0.73, M=0.2, J=0.01, \gamma=4.0$ and $\varepsilon=5.0$. Surface becomes more 
roughened for increasing values of amplitude-to-length ratio of wavy surface. Velocity force decreases at the local points. However, the maximum values of the skin friction coefficient and the heat transfer rate are 2.17998 and 0.64624 for $\alpha=0.0$ respectively which attains at the surface and 2.06092 and 0.62702 for $\alpha=0.4$ respectively which occurs at the axial position of $x=0.50$. It is seen that the skin friction coefficient and the heat transfer rate decrease by $5.46 \%$ and $2.97 \%$ respectively as $\alpha$ increases from 0.0 to 0.4 .
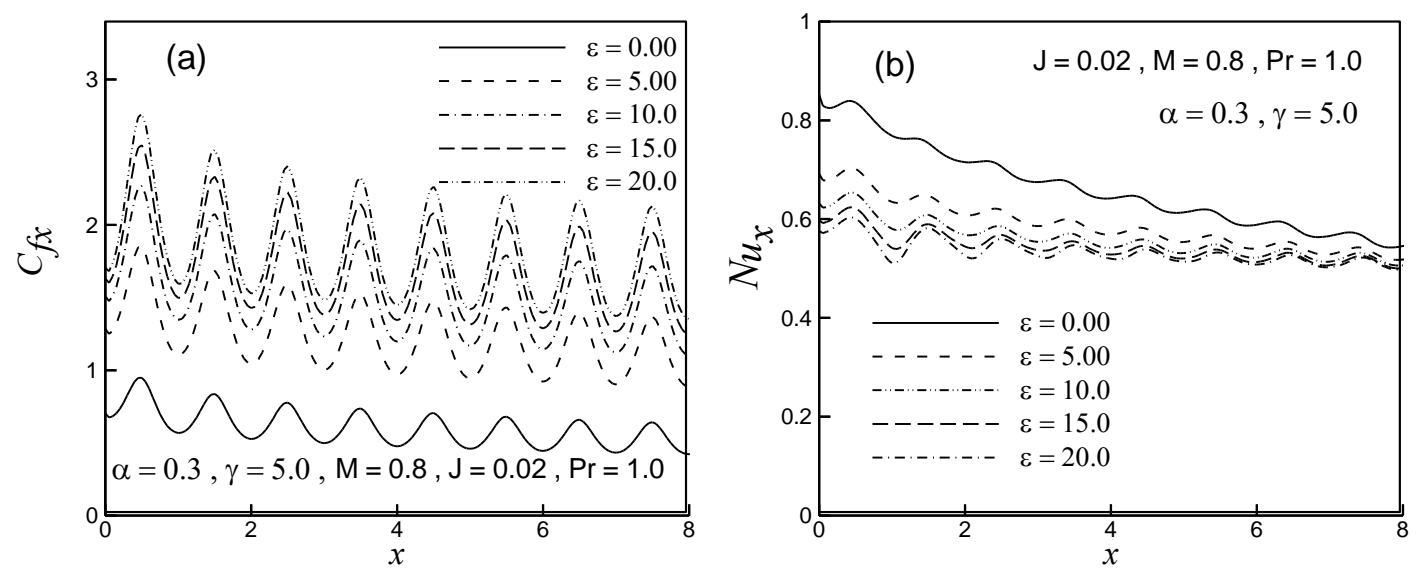

Fig. 4: Effect of $\varepsilon$ on (a) skin friction coefficient $C_{f x}$ and (b) rate of heat transfer $N u_{x}$.
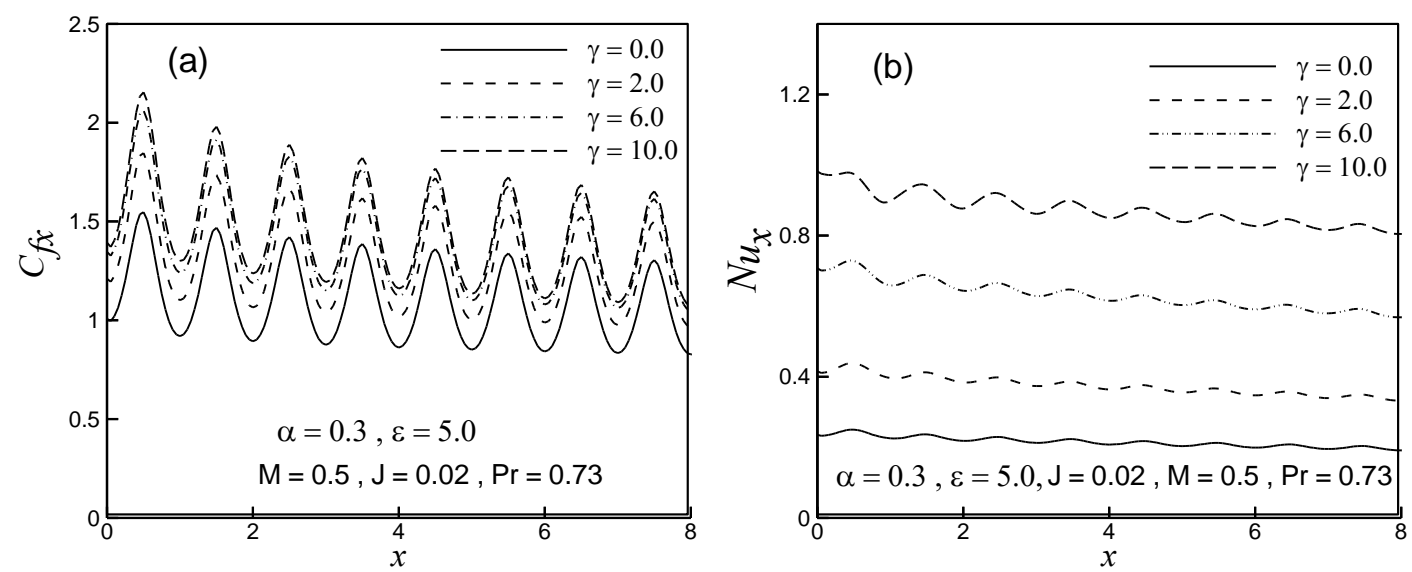

Fig. 5: Effect of $\gamma$ on (a) skin friction coefficient $C_{f x}$ and (b) rate of heat transfer $N u_{x}$.

Figs. 7(a) and 7(b) deal with the effect of $J$ on the velocity $f^{\prime}(x, \eta)$ and the temperature $\theta(x, \eta)$ within the boundary layer for different values of the controlling parameters $\gamma=4.0, \varepsilon=5.0, \alpha=0.3, M=0.02$ and $\operatorname{Pr}=$ 0.5. From Fig. 7(a), it is revealed that the velocity increases very slowly with the increase of Joule heating parameter which indicates that Joule heating accelerates the fluid motion. But for free convection near the surface of the plate velocity increases and becomes maximum and then decreases and finally approaches to zero asymptotically. Small increment is shown from Fig. 7(b) on the temperature for increasing values of $J$. Moreover, the highest values of the velocity are $0.55037,0.55053,0.55425,0.55813$ and 0.56589 for $J=0.0$, $0.02,0.50,1.0$ and 2.0 respectively and each of which occurs at the same value of $\eta=3.06886$. It is seen that the velocity increases by only $2.74 \%$ when the value of $J$ changes from 0.0 to 2.0 .

Fig. 8(a) demonstrates the velocity for variation of viscosity parameter with other fixed parameters $\operatorname{Pr}=1.0, M$ $=0.8, J=0.02, \alpha=0.3$ and $\gamma=5.0$ and the corresponding temperature $\theta(x, \eta)$ is shown in Fig. 8(b). Increasing viscosity decreases the velocity gradient normal to the wall. That is why the velocity of the fluid reduces quickly with the increase of the temperature dependent viscosity parameter. The maximum values of the velocity are 0.61747 and 0.27130 for $\varepsilon=0.0$ and 20.0 respectively. It is observed that the velocity decreases by approximately $56 \%$ as $\varepsilon$ increases from 0.0 to 20.0 which occur at the different position of $\eta$. On the other hand the temperature increases within the boundary layer with the increasing values of viscosity parameter. Viscosity is proportional to linear function of temperature. So the increasing value of viscosity parameter increases the 
temperature difference between the surface and ambient temperature of the fluid. Then heat is transferred rapidly from surface to fluid within the boundary layer.
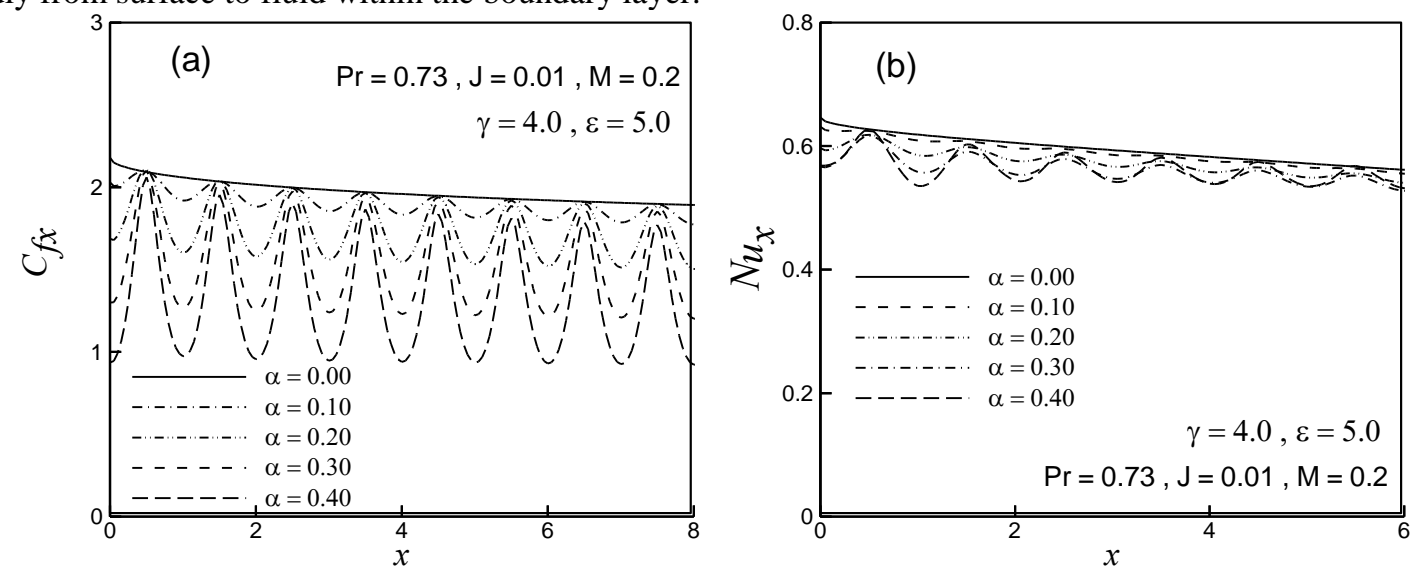

Fig. 6: Effect of $\alpha$ on (a) skin friction coefficient $C_{f x}$ and (b) rate of heat transfer $N u_{x}$.
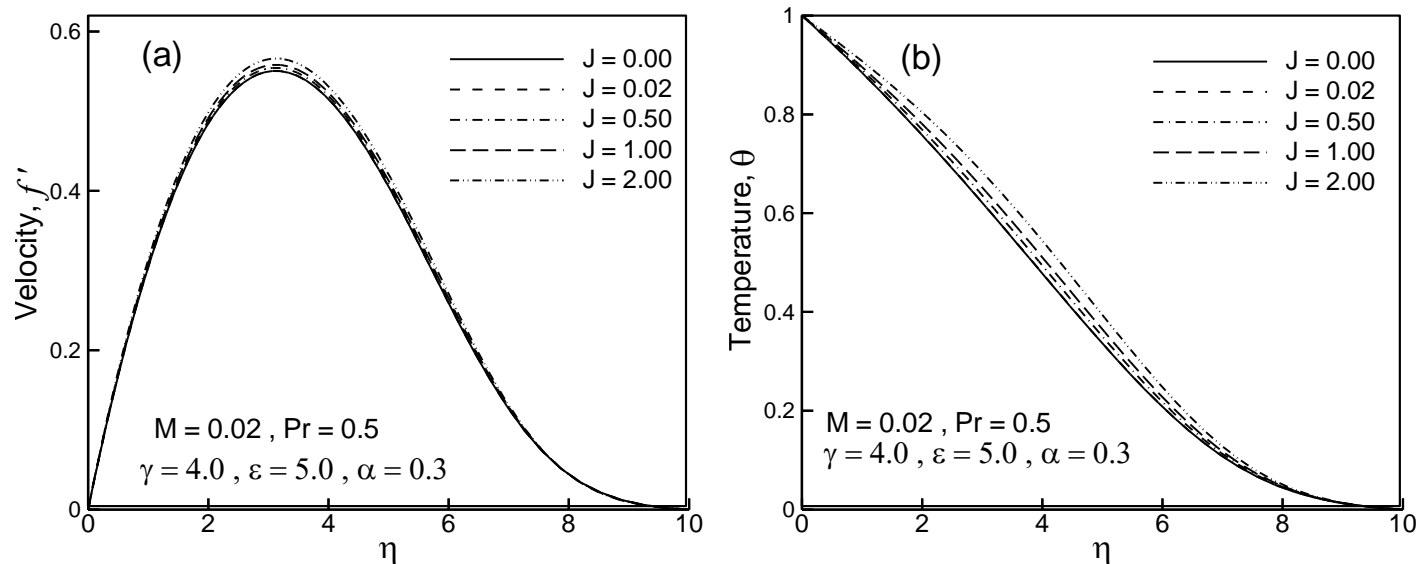

Fig. 7: Effect of $J$ on (a) velocity profiles $f^{\prime}$ and (b) temperature distribution $\theta$
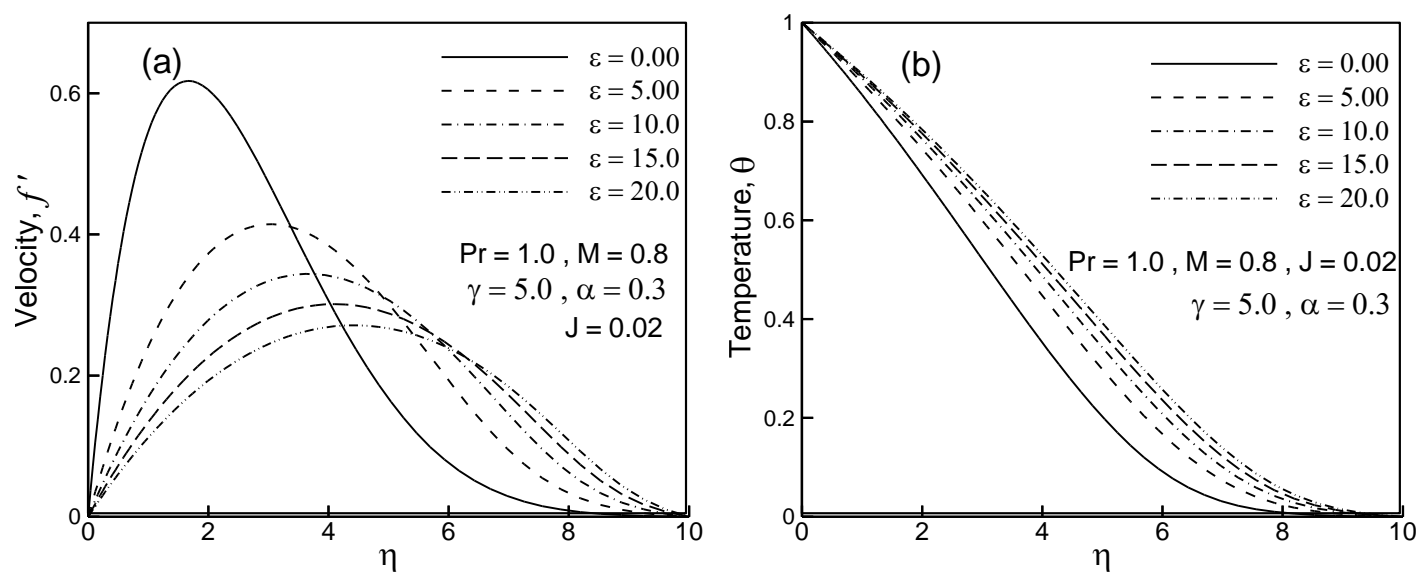

Fig. 8: Effect of $\varepsilon$ on (a) velocity profiles $f^{\prime}$ and (b) temperature distribution $\theta$

The variation of temperature dependent thermal conductivity parameter $\gamma$ on the velocity $f^{\prime}(x, \eta)$ and the temperature $\theta(x, \eta)$ within the boundary layer with other fixed parameters, $\alpha=0.3, M=0.5, \varepsilon=5.0, J=0.02$ and $\operatorname{Pr}=0.73$ are displayed in Fig. 9(a) and 9(b) respectively. As $\gamma=\gamma^{*}\left(T_{w}-T_{\infty}\right)$, so the increasing value of $\gamma$ increases the temperature difference between the surface and ambient temperature of the fluid. Then heat is transferred rapidly from surface to fluid within the boundary layer. For this reason both the velocity and temperature increase with the increasing value of $\gamma$. Moreover, the maximum values of velocity are found to be Joule heating and MHD free convection flow along a vertical wavy surface with viscosity ...... 
$0.31981,0.40832,0.48808$ and 0.52366 for $\gamma=0.0,2.0,6.0$ and 10.0 respectively and each of which occurs at different position of $\eta$. It is observed that the velocity increases by approximately $39 \%$ as $\gamma$ changes from 0 to 10.0 .
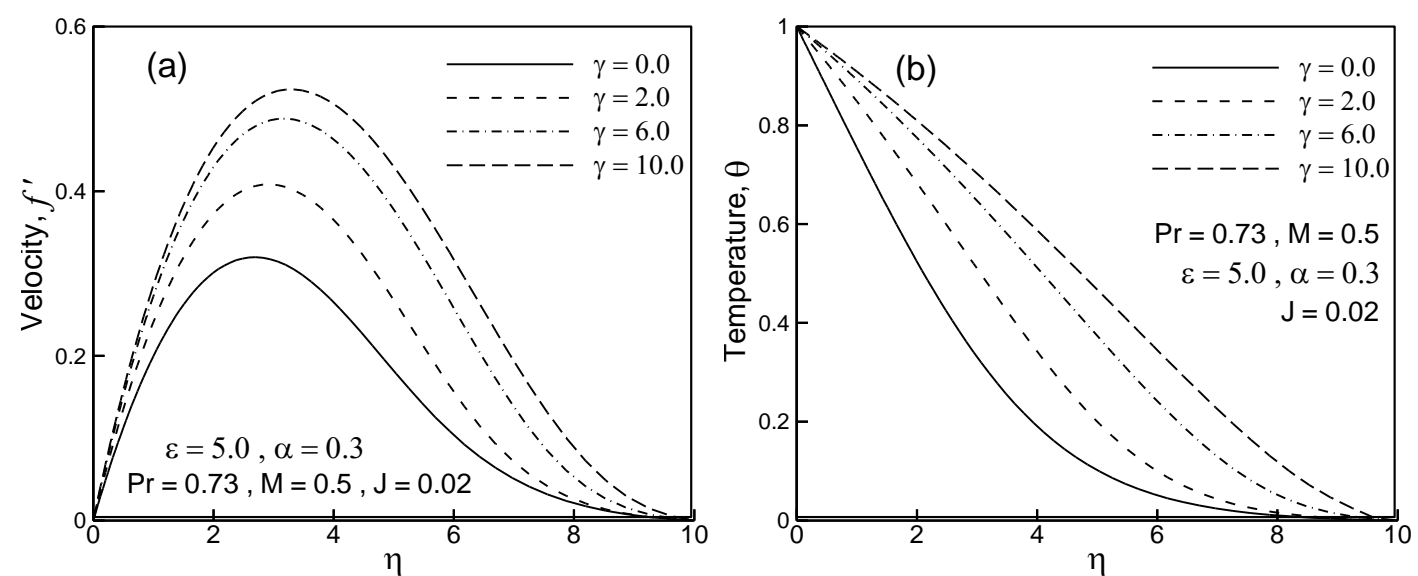

Fig. 9: Effect of $\gamma$ on (a) velocity profiles $f^{\prime}$ and (b) temperature distribution $\theta$

Figs. 10 and 11 illustrate the effect of Joule heating parameter on the development of streamlines and isotherms profile which are plotted for $\alpha=0.3, \operatorname{Pr}=0.5, \varepsilon=5.0, \gamma=4.0$ and $M=0.02$. Joule heating is the heating effect of conductors carrying currents. So the velocity and thermal boundary layer become thicker with the increasing values of $J$. This happens, because the buoyancy forces increases, including the flow rate increase within the boundary layer. The maximum values of $\psi$, that is, $\psi_{\max }$ are 13.22, 14.45, 15.28 and 16.31 for Joule heating parameter $J=0.0,0.06,0.10$ and 0.15 respectively.

The effect for different values of $\varepsilon$ equal to $0.0,5.0,10.0$ and 15.0 on the streamlines and isotherms profile are shown in Figs. 12 and 13 respectively while $\operatorname{Pr}=1.0, \alpha=0.3, J=0.02, \gamma=5.0$ and $M=0.8$. From Fig. 12, it is noted that the maximum values of $\psi$ decreases steadily while the value of viscosity parameter increases. The maximum values of $\psi$, that is, $\psi_{\max }$ are $8.14,6.69,5.88$ and 5.29 for viscosity parameter $\varepsilon=0.0,5.0,10.0$ and 15.0 respectively. It is also observed that as the values of viscosity parameter increase the thermal boundary layer becomes thicker gradually. Finally, it is concluded that for the effect of $\varepsilon$ the velocity of the fluid flow decreases and temperature distribution within the boundary layer increases.
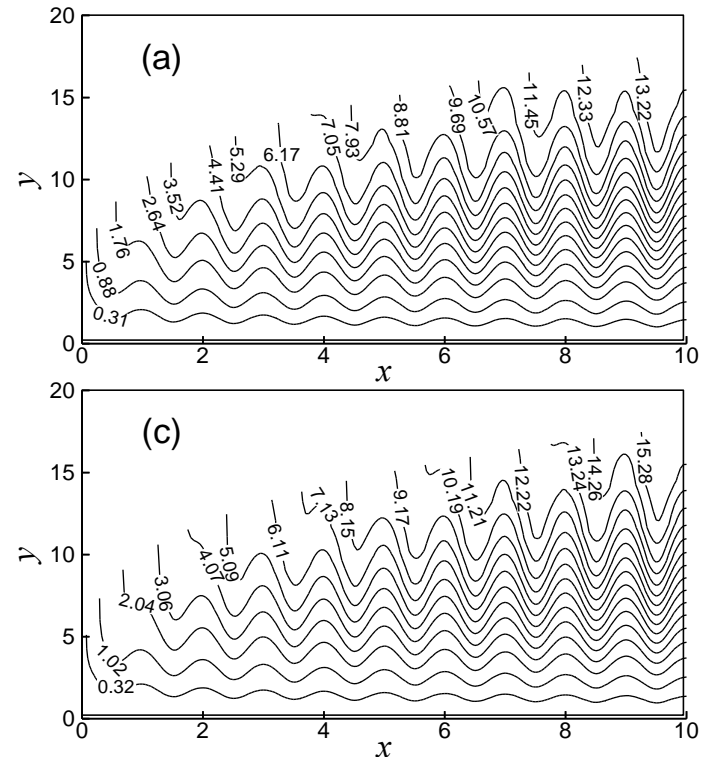
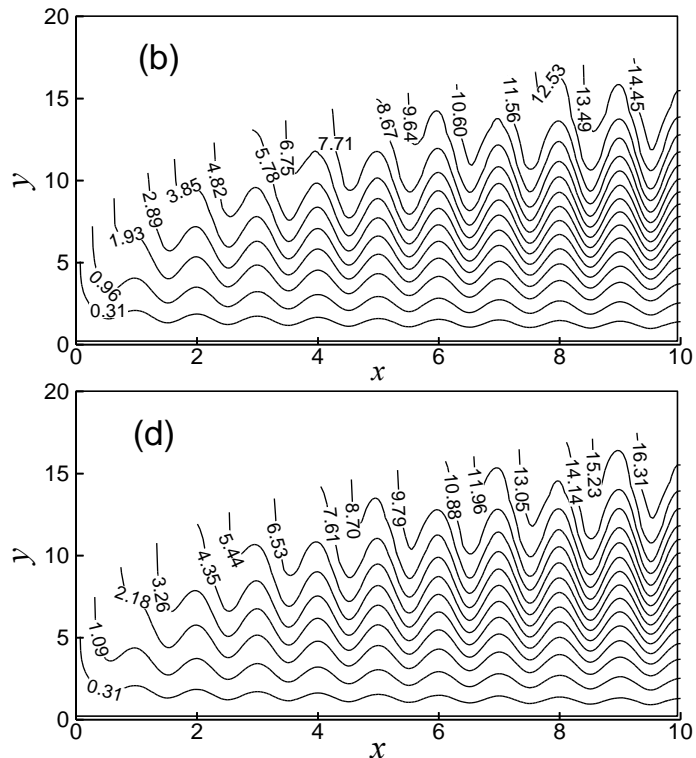

Fig. 10: Streamlines for (a) (a) $J=0.0$ (b) $J=0.06$ (c) $J=0.10$ (d) $J=0.15$ while $\alpha=0.3, \operatorname{Pr}=0.5$, $\varepsilon=5.0, \gamma=4.0$ and $M=0.02$. 

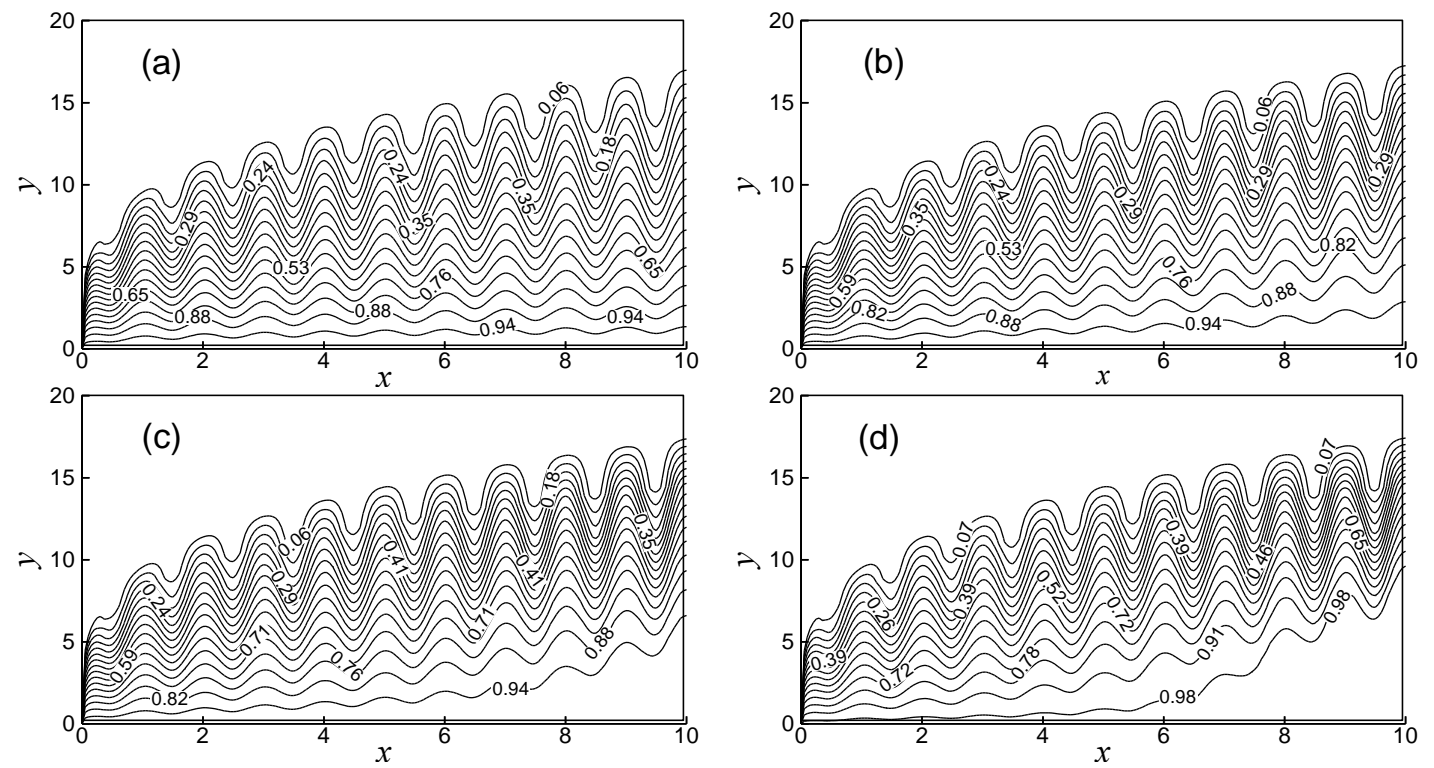

Fig. 11: Isotherms for (a) (a) $J=0.0$ (b) $J=0.06$ (c) $J=0.10$ (d) $J=0.15$ while $\alpha=0.3, \operatorname{Pr}=0.5$, $\varepsilon=5.0, \gamma=4.0$ and $M=0.02$.

The influence of $\gamma$ on the development of streamlines and isotherms are plotted in Figs. 14 and 15 respectively for $\operatorname{Pr}=0.73, \alpha=0.3, J=0.02, \varepsilon=5.0$ and $M=0.5$. It is noted that for $\gamma$ equal to $0.0,2.0,6.0$ and 10.0 the maximum values of $\psi$, that is, $\psi_{\max }$ are 5.41, 7.37, 9.05 and 9.68 respectively. So from this figure, it is seen that for the effect of $\gamma$, the flow rate in the boundary layer increases and velocity boundary layer grows thick. The same result also observed for the thermal boundary layer.
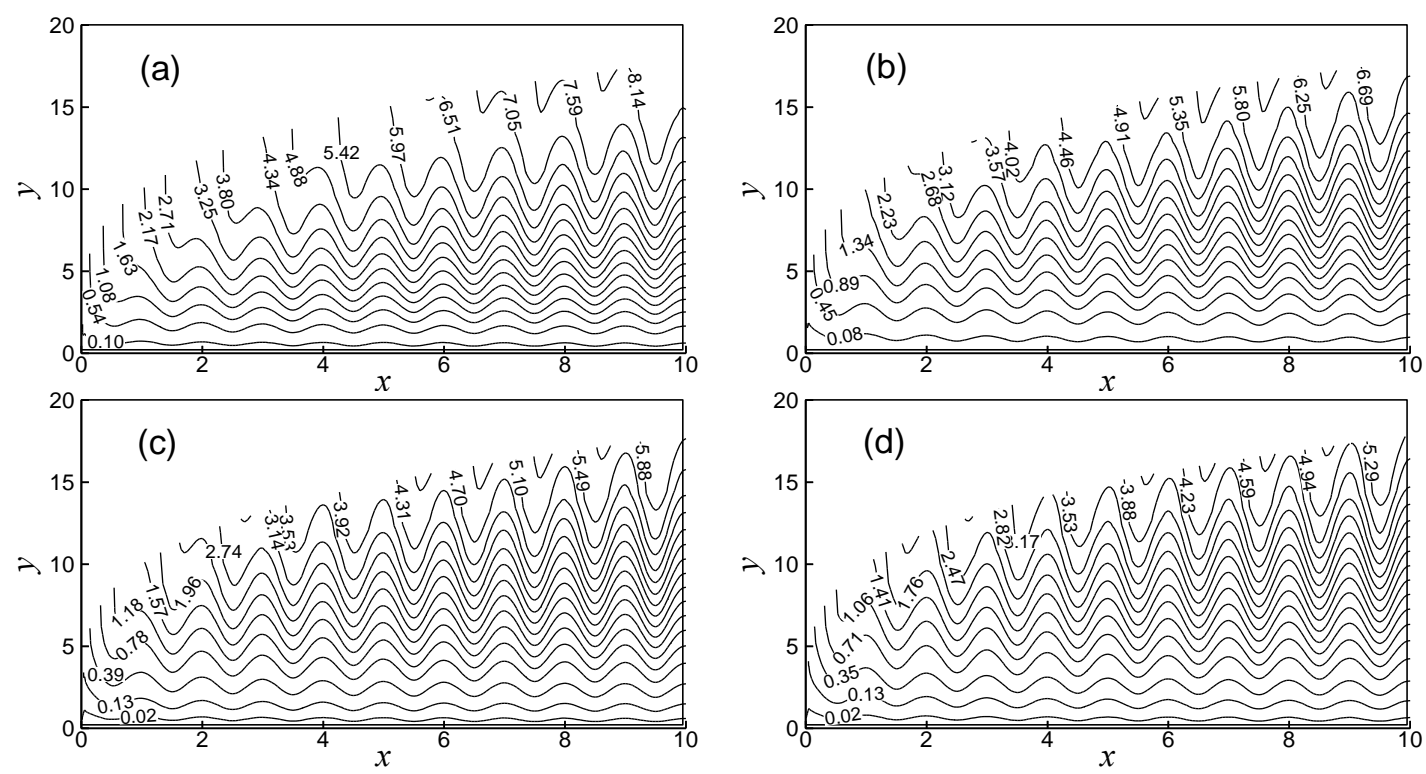

Fig. 12: Streamlines for (a) $\varepsilon=0.0$ (b) $\varepsilon=5.0$ (c) $\varepsilon=10.0$ (d) $\varepsilon=15.0$ while $\operatorname{Pr}=1.0, \alpha=0.3, J=0.02$, $\gamma=5.0$ and $M=0.8$. 

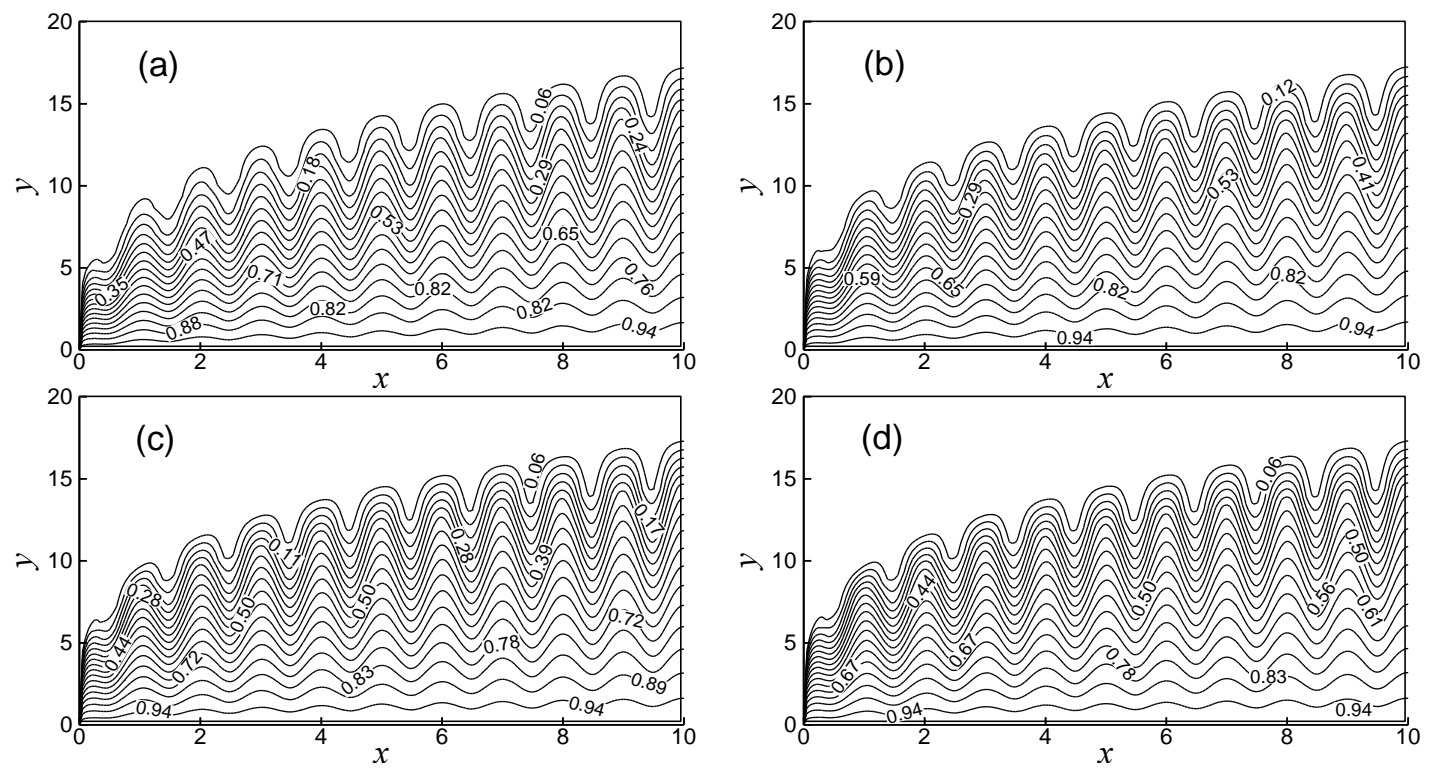

Fig. 13: Isotherms for (a) $\varepsilon=0.0$ (b) $\varepsilon=5.0$ (c) $\varepsilon=10.0$ (d) $\varepsilon=15.0$ while $\operatorname{Pr}=1.0, \alpha=0.3, J=0.02$, $\gamma=5.0$ and $M=0.8$.
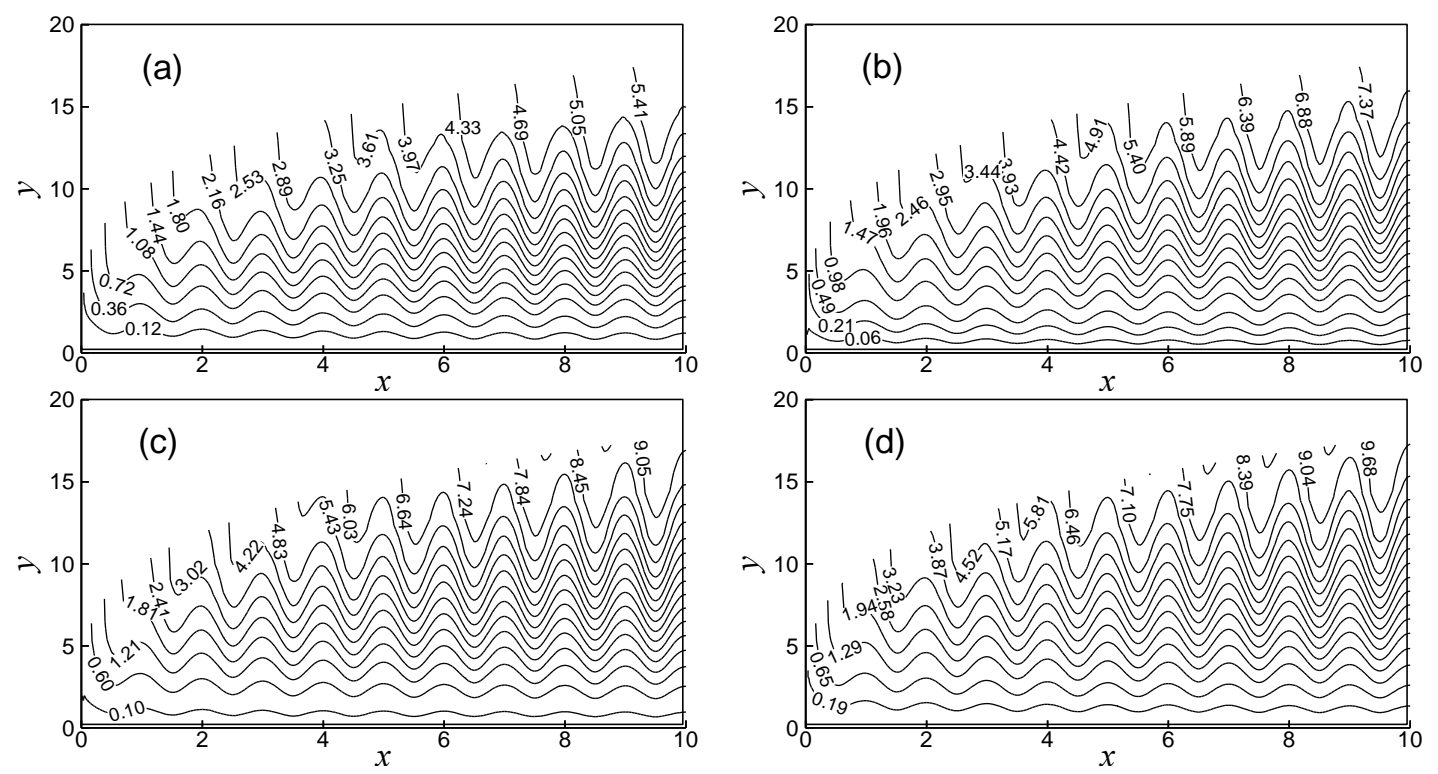

Fig. 14: Streamlines for (a) $\gamma=0.0$ (b) $\gamma=2.0$ (c) $\gamma=6.0$ (d) $\gamma=10.0$ while $\operatorname{Pr}=0.73, \alpha=0.3, J=0.02$, $\varepsilon=5.0$ and $M=0.5$.

The values of skin friction coefficient $C_{f x}$ and the rate of heat transfer in terms of the local Nusselt number $N u_{x}$ for variation of Joule heating parameter $(J=0.0,0.06,0.15)$ while $\alpha=0.3, M=0.02, \gamma=4.0, \varepsilon=5.0$ and $\operatorname{Pr}=$ 0.5 are entered in Table 1. It is noted that the complete cycle of the wavy surface is from $x=0.0$ to 5.0. The skin friction coefficient $C_{f x}$ and the rate of heat transfer increase for the first quarter of the cycle ( $x \cong 0$ to $x \cong 0.50$ ) and decrease in the second quarter $(x \cong 0.50$ to $x \cong 1.0)$. From $x \cong 1.0$ to $\cong 1.5$ (i.e., third quarter) the skin friction coefficient $C_{f x}$ again increases, where as the fourth quarter $(x \cong 1.5$ to $x \cong 2.0)$ it decreases. The skin friction coefficient $C_{f x}$ and the rate of heat transfer in terms of the local Nusselt number $N u_{x}$ show similar characteristics throughout the domain. However, the maximum values of local skin friction coefficient $C_{f x}$ are recorded to be $2.27275,2.27550$ and 2.27963 for $J=0.0,0.06$ and 0.15 respectively. Moreever, the maximum values of the rate of heat transfer in terms of the local Nusselt number $N u_{x}$ are recorded to be $0.56347,0.55958$ and 0.55372 for $J=0.0,0.06$ and 0.15 respectively. It is seen that the local skin friction coefficient $C_{f x}$ increases by only 
$0.30 \%$. and the rate of heat transfer $N u_{x}$ decreases by $1.73 \%$ as $J$ increases from 0.0 to 0.15 . Both are occurs at the same value of $x=0.50$.
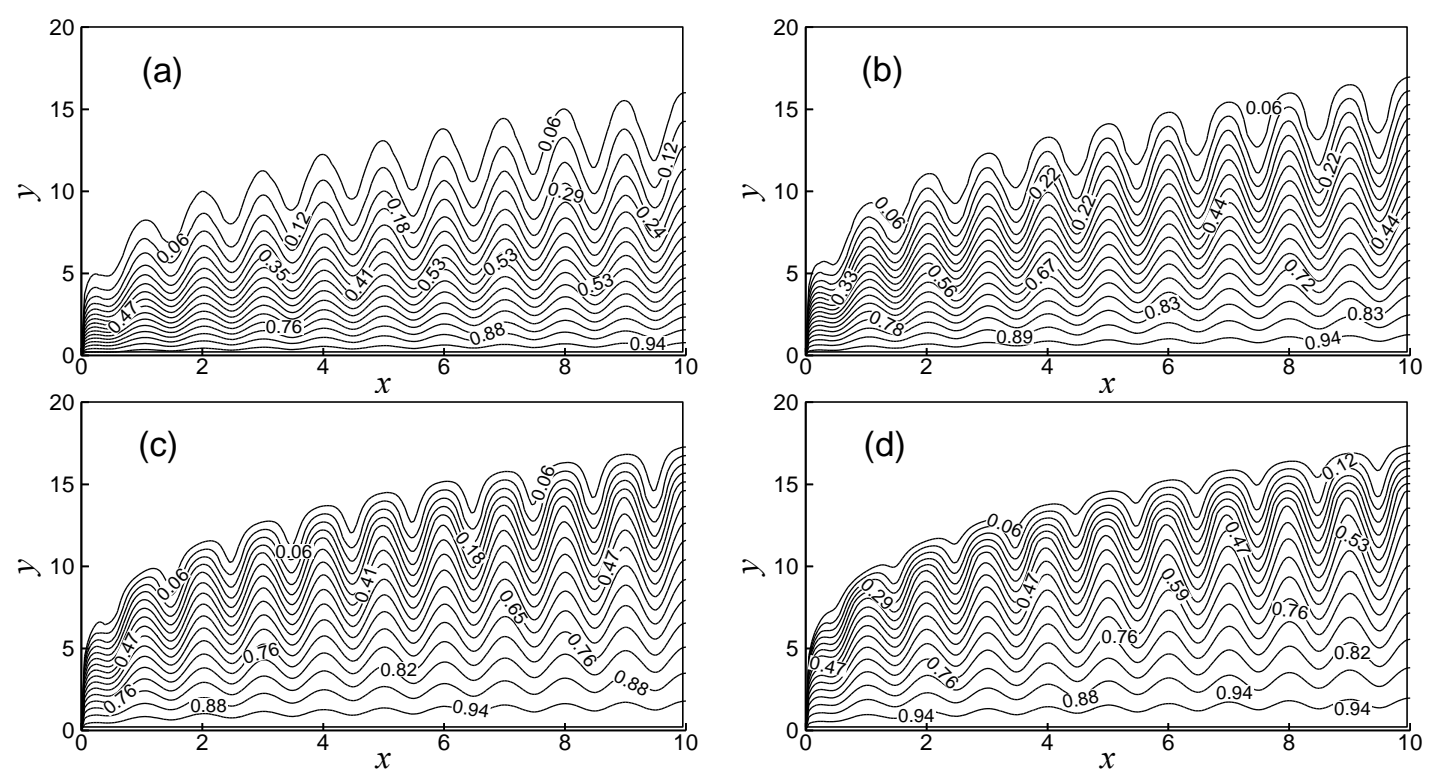

Fig. 15: Isotherms for (a) $\gamma=0.0$ (b) $\gamma=2.0$ (c) $\gamma=6.0$ (d) $\gamma=10.0$ while $\operatorname{Pr}=0.73, \alpha=0.3, J=0.02$, $\varepsilon=5.0$ and $M=0.5$.

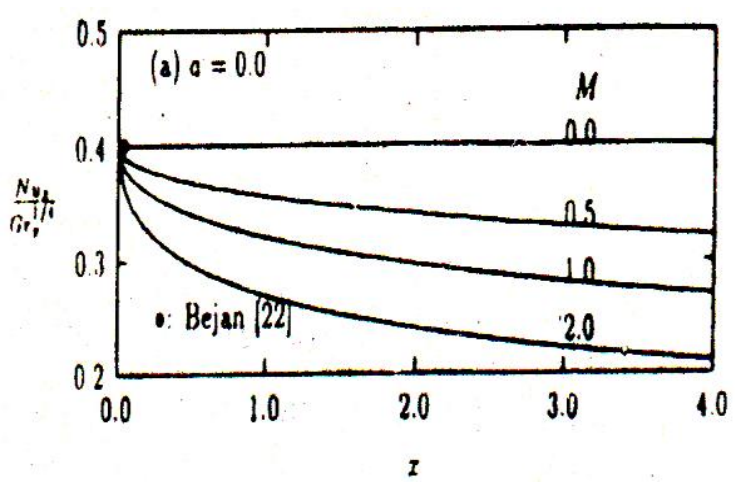

Fig. 16: Local Nusselt number for different values of magnetic parameter $M$ with $\operatorname{Pr}=1.0, \alpha=$ $0.0, \gamma=0.0, J=0.0$ and $\varepsilon=0.0$ (Alam et al. (1997)).

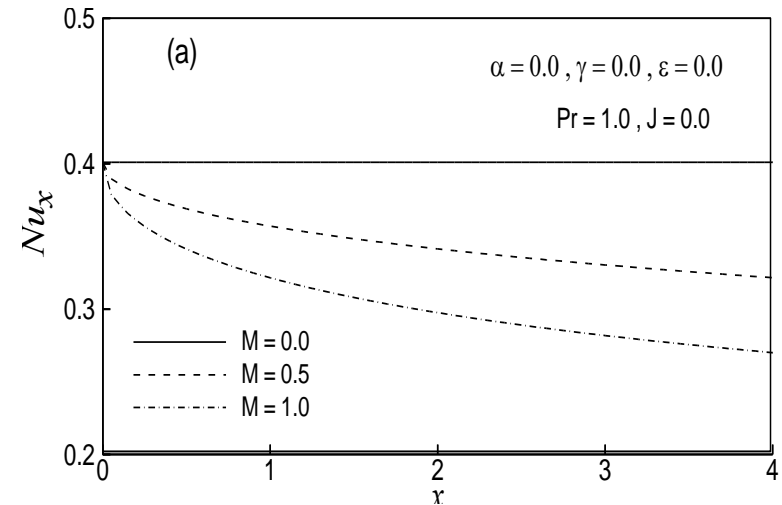

Fig. 17: Local Nusselt number for different values of magnetic parameter $M$ with $\operatorname{Pr}=1.0, \alpha=0.0, \gamma$ $=0.0, J=0.0$ and $\varepsilon=0.0$ (present work).

In Table 2, the numerical values of skin friction coefficient $C_{f x}$ against $x$ for different values of viscosity variation parameter (with and without effect of $J$ ) with other fixed controlling values $M=0.8, \operatorname{Pr}=1.0, \gamma=5.0$ and $\alpha=0.3$ are shown. It is observed from this table that the values of skin friction coefficient $C_{f x}$ at different position of $x$ for $\varepsilon=0.0,5.0,10.0$ and 20.0 are smaller when Joule heating parameter is not used $(J=0.0)$ than that of using Joule heating parameter $(J=0.02)$. The skin friction coefficient $C_{f x}$ increases is around $65.68 \%$ as $\varepsilon$ changes from 0.0 to 20.0 at the axial position of $x=0.50$ when there is no effect of Joule heating parameter. But applying the effect of Joule heating parameter $(J=0.02)$ the skin friction coefficient $C_{f x}$ increases is around $65.70 \%$ as $\varepsilon$ changes from 0.0 to 20.0 at the same axial position of $x$.

The numerical values of rate of heat transfer $N u_{x}$ against $x$ for the variation of thermal conductivity parameter (with and without effect of $J$ ) with other fixed parameters $M=0.5, \operatorname{Pr}=0.73, \varepsilon=5.0$ and $\alpha=0.3$ are shown in Table 3. It is noted that the values of rate of heat transfer $N u_{x}$ for $\gamma=0.0,2.0,6.0$ and 10.0 are higher at different position of $x$ when Joule heating parameter is not considered $(J=0.0)$ than that of using Joule heating parameter $(J=0.02)$. At the axial position of $x=0.50$ the rate of heat transfer $N u_{x}$ increases is around $74.32 \%$ as $\gamma$ changes from 0.0 to 10.0 when there is no effect of Joule heating parameter. But in presence of Joule heating parameter 
$(J=0.02)$ the rate of heat transfer $N u_{x}$ increases is around $74.26 \%$ as $\gamma$ changes from 0.0 to 10.0 at the same axial position $x$.

Table 1: Skin friction coefficient $C_{f x}$ and the rate of heat transfer in terms of Nusselt number $N u_{x}$ for variation of Joule heating parameter $(J=0.0,0.06,0.15)$ with other fixed controlling parameters $\alpha=0.3, M=$ $0.02, \gamma=4.0, \varepsilon=5.0$ and $\operatorname{Pr}=0.5$.

\begin{tabular}{ccccccc}
\hline \multirow{2}{*}{$x$} & \multicolumn{3}{c}{ Skin friction coefficient $C_{f x}$} & \multicolumn{2}{c}{ Rate of heat transfer $N u_{x}$} \\
\cline { 2 - 6 } & $J=0.0$ & $J=0.06$ & $J=0.15$ & $J=0.0$ & $J=0.06$ & $J=0.15$ \\
\hline 0.00 & 1.33816 & 1.33816 & 1.33816 & 0.52014 & 0.52015 & 0.52015 \\
0.50 & 2.27275 & 2.27550 & 2.27963 & 0.56347 & 0.55958 & 0.55372 \\
1.00 & 1.38357 & 1.38770 & 1.39395 & 0.51095 & 0.50376 & 0.49284 \\
1.50 & 2.23131 & 2.24309 & 2.26100 & 0.55161 & 0.53438 & 0.50794 \\
2.00 & 1.38659 & 1.39829 & 1.41620 & 0.51747 & 0.49615 & 0.46302 \\
2.50 & 2.20677 & 2.23119 & 2.26890 & 0.54714 & 0.51157 & 0.45559 \\
3.00 & 1.39261 & 1.41435 & 1.44818 & 0.52008 & 0.47983 & 0.41539 \\
3.50 & 2.18803 & 2.22784 & 2.29044 & 0.54430 & 0.48620 & 0.39196 \\
4.00 & 1.39718 & 1.43103 & 1.48473 & 0.52130 & 0.45793 & 0.35296 \\
4.50 & 2.17388 & 2.23152 & 2.32402 & 0.54261 & 0.45810 & 0.31626 \\
5.00 & 1.40019 & 1.44797 & 1.52539 & 0.52181 & 0.43143 & 0.27603 \\
\hline
\end{tabular}

Table 2: Comparison of skin friction coefficient $C_{f x}$ against $x$ for the variation of viscosity parameter $(\varepsilon=0.0$, $5.0,10.0,20.0$ ) with and without effect of $J$ with other fixed parameters $M=0.8, \operatorname{Pr}=1.0, \gamma=5.0$ and $\alpha=0.3$.

\begin{tabular}{ccccccccc}
\hline$x$ & \multicolumn{7}{c}{ Skin friction coefficient $C_{f x}$} \\
\cline { 2 - 8 } & \multicolumn{2}{c}{$\varepsilon=0.0$} & \multicolumn{2}{c}{$\varepsilon=5=10.0$} & \multicolumn{2}{c}{$\varepsilon=20.0$} \\
\cline { 2 - 9 } & $J=0.0$ & $J=0.02$ & $J=0.0$ & $J=0.02$ & $J=0.0$ & $J=0.02$ & $J=0.0$ & $J=0.02$ \\
\hline 0.00 & 0.70328 & 0.70328 & 1.28671 & 1.28671 & 1.51106 & 1.51106 & 1.70544 & 1.70544 \\
0.50 & 0.94819 & 0.94844 & 1.85247 & 1.85317 & 2.26779 & 2.26859 & 2.76283 & 2.76364 \\
1.00 & 0.56820 & 0.56856 & 1.10422 & 1.10514 & 1.34618 & 1.34721 & 1.59428 & 1.59513 \\
1.50 & 0.83657 & 0.83743 & 1.68208 & 1.68443 & 2.07328 & 2.07588 & 2.51554 & 2.51783 \\
2.00 & 0.52608 & 0.52695 & 1.04200 & 1.04420 & 1.27656 & 1.27897 & 1.52639 & 1.52843 \\
2.50 & 0.77671 & 0.77821 & 1.58741 & 1.59154 & 1.96675 & 1.97130 & 2.40154 & 2.40556 \\
\hline
\end{tabular}

Table 3: Comparison of rate of heat transfer $N u_{x}$ against $x$ for the variation of thermal conductivity parameter $(\gamma=0.0,2.0,6.0,10.0)$ with and without effect of $J$ with other fixed controlling values $M=0.5$, Pr $=0.73, \varepsilon=5.0$ and $\alpha=0.3$.

\begin{tabular}{ccccccccc}
\hline$x$ & \multicolumn{7}{c}{ Rate of heat transfer $N u_{x}$} \\
\cline { 2 - 8 } & \multicolumn{2}{c}{$\gamma=0.0$} & \multicolumn{2}{c}{$\gamma=2.0$} & \multicolumn{2}{c}{$\gamma=6.0$} & \multicolumn{2}{c}{$\gamma=10.0$} \\
\cline { 2 - 9 } & $J=0.0$ & $J=0.02$ & $J=0.0$ & $J=0.02$ & $J=0.0$ & $J=0.02$ & $J=0.0$ & $J=0.02$ \\
\hline 0.00 & 0.23573 & 0.23573 & 0.41570 & 0.41570 & 0.70763 & 0.70763 & 0.98251 & 0.98251 \\
0.50 & 0.25070 & 0.25035 & 0.43968 & 0.43889 & 0.72996 & 0.72840 & 0.97633 & 0.97420 \\
1.00 & 0.22614 & 0.22549 & 0.39765 & 0.39625 & 0.66149 & 0.65879 & 0.90160 & 0.89805 \\
1.50 & 0.23824 & 0.23684 & 0.41571 & 0.41254 & 0.69442 & 0.68831 & 0.95044 & 0.94232 \\
2.00 & 0.22026 & 0.21848 & 0.38807 & 0.38423 & 0.65078 & 0.64358 & 0.88605 & 0.87668 \\
2.50 & 0.23206 & 0.22932 & 0.40423 & 0.39811 & 0.67679 & 0.66519 & 0.93390 & 0.91882 \\
\hline
\end{tabular}


Table 4: Comparison of the present numerical results of skin friction coefficient, $C_{f x}$ with Parveen and Alim (2011) for the variation of $\operatorname{Pr}$ and $\varepsilon$ while $M=0.0, J=0.0, \gamma=0.0$ and $\alpha=0.4$.

\begin{tabular}{|c|c|c|c|c|c|c|c|c|}
\hline \multirow{4}{*}{$\varepsilon$} & \multicolumn{9}{|c|}{ Skin friction coefficient, $C_{f x}$} \\
\cline { 2 - 8 } & \multicolumn{2}{|c|}{$\operatorname{Pr}=1.0$} & \multicolumn{2}{c|}{$\operatorname{Pr}=10.0$} & \multicolumn{2}{c|}{$\operatorname{Pr}=25.0$} & \multicolumn{2}{c|}{$\operatorname{Pr}=100.0$} \\
\cline { 2 - 9 } & $\begin{array}{c}\text { Parveen } \\
\text { and Alim } \\
(2011)\end{array}$ & $\begin{array}{c}\text { Present } \\
\text { work }\end{array}$ & $\begin{array}{c}\text { Parveen } \\
\text { and Alim } \\
(2011)\end{array}$ & $\begin{array}{c}\text { Present } \\
\text { work }\end{array}$ & $\begin{array}{c}\text { Parveen } \\
\text { and Alim } \\
(2011)\end{array}$ & $\begin{array}{c}\text { Present } \\
\text { work }\end{array}$ & $\begin{array}{c}\text { Parveen } \\
\text { and Alim } \\
(2011)\end{array}$ & $\begin{array}{c}\text { Present } \\
\text { work }\end{array}$ \\
\hline 0.0 & 0.925 & 0.931 & 0.608 & 0.616 & 0.500 & 0.507 & 0.365 & 0.371 \\
1.0 & 1.153 & 1.153 & 0.759 & 0.736 & 0.623 & 0.600 & 0.452 & 0.433 \\
2.0 & 1.300 & 1.301 & 0.842 & 0.817 & 0.690 & 0.650 & 0.497 & 0.476 \\
\hline
\end{tabular}

\section{Comparison with previous work and code validation}

The influence of the magnetic parameter $M$, on the local Nusselt number are illustrated in Figs. 16 and 17 respectively while $\operatorname{Pr}=1.0, \alpha=0.0, \gamma=0.0, \varepsilon=0.0$ and $J=0.0$. The results for constant viscosity $(\varepsilon=0.0)$, constant thermal conductivity $(\gamma=0.0)$, without Joule heating $(J=0.0)$ and a fluid having $\operatorname{Pr}=1.0$ are compared with those of Alam et al. (1997) and a very good agreement is found.

Table 4 also depicts the comparison of the current numerical results of the skin friction coefficient $C_{f x}$ with the results obtained by Parveen and Alim (2011). Here the magnetic parameter $M$, thermal conductivity parameter $\gamma$ and Joule heating parameter $J$ are ignored with different values of Prandtl number $\operatorname{Pr}=(1.0,10,25.0$ and 100.0) and viscosity variation parameter $\varepsilon=(0.0,1.0,2.0)$ are chosen. From Table 4 , it is clearly seen that the present results are excellent agreement with the solution of Parveen and Alim (2011). These validations boost the confidence in the numerical code to carry on with the above stated objectives of the current investigation.

\section{Conclusion}

The problem of free convection heat transfer along a vertical wavy surface with the effect of Joule heating and magnetic field in presence of temperature dependent variable viscosity and thermal conductivity has been analyzed. The effects of Joule heating parameter, viscosity parameter, the amplitude-to-length ratio of wavy surface and thermal conductivity parameter on momentum and heat transfer have been studied in detail. The outcomes of the existing analysis are:

- The local skin friction coefficient increase noticeably for the growing values of Joule heating parameter $J$, temperature dependent viscosity parameter $\varepsilon$ and temperature dependent thermal conductivity parameter $\gamma$.

- An increase in the values of $J, \alpha$ and $\varepsilon$ lead to a significant decrease in the local rate of heat transfer.

- The velocity of fluid flow within the boundary layer radically increases for increasing values of $\gamma$ and $J$ and decreases for increasing values of $\varepsilon$.

- The temperature distribution of the fluid flow within the boundary layer rise considerably for the increasing values of Joule heating parameter, temperature dependent viscosity parameter and temperature dependent thermal conductivity parameter as well as the thermal boundary layer grow thick.

- When viscosity is constant then both of the skin friction coefficient and velocity either increase or decrease. But from the present work, it is concluded that when viscosity is dependent on temperature then opposite results are obtained. In this case the skin friction coefficient increases and the velocity decreases.

- Temperature dependent thermal conductivity has noteworthy effect both on temperature and heat transfer rate. Both of the temperature and the rate of heat transfer in terms of local Nusselt number increase for the increasing values of temperature dependent thermal conductivity. 


\section{References}

Alam, K. C. A., Hossain, M. A. and Rees, D. A. S. (1997): Magnetohydrodynamic Free Convection along a Vertical Wavy Surface, Int. J. Appl. Mech. Engrg., Vol. 1, pp. 555-566.

Alim, M. A., Alam, M. and Mamun, A. A. (2007): Joule Heating Effect on the Coupling of Conduction with MHD Free Convection Flow from a Vertical Flat Plate, Nonlinear Analysis: Modell. and Cont., Vol. 12, pp. 307-316.

Alim, M. A., Alam, M. M., Mamun, A. A. and Hossain, M. B. (2008): Combined Effect of Viscous Dissipation $\&$ Joule Heating on the Coupling of Conduction \& Free Convection along a Vertical Flat Plate, Int. Commun. in Heat and Mass Transfer, Vol. 35, pp. 338-346. http://dx.doi.org/10.1016/j.icheatmasstransfer.2007.06.003

Cebeci, T. and Bradshaw, P. (1984): Physical and Computational Aspects of Convective Heat Transfer, Springer, New York. http://dx.doi.org/wiley.com/10.1002/zamm.19860661123

Charraudeau, J. (1975): Influence De Gradients De Properties Physiques En Convection Force Application Au Cas Du Tube, Int. J. Heat Mass Tran., Vol. 18, pp. 87-95.

Cheng, C. Y. (2000): Natural Convection Heat and Mass Transfer Near a Vertical Wavy Surface with Constant Wall Temperature and Concentration in a Porous Medium, Int. Comm. Heat and Mass Transfer, Vol. 27, pp. 1143-1154.

Elbashbeshy, E. M. A. (2000): Free Convection Flow with Variable Viscosity and Thermal Diffusivity along a Vertical Plate in the Presence of Magnetic Field, Int. J. Eng. Science, Vol. 38, pp. 207-213. http://dx.doi.org/10.1016/S0020-7225(99)00021-X

Hossain, M. A. (1992): The Viscous and Joule Heating Effects on MHD Free Convection Flow with Variable Plate Temperature, Int. J. Heat and Mass Transfer, Vol. 35, pp. 3485-3487. http://dx.doi.org/10.1016/00179310(92)90234-J

Hossain, M. A. and Rees, D. A. S. (1999): Combined Heat and Mass Transfer in Natural Convection Flow from a Vertical Wavy Surface, Acta Mechanica, Vol. 136, pp. 133-141.

Hossain, M. A., Munir, M. S. and Rees, D. A. S. (2000): Flow of Viscous Incompressible Fluid with Temperature Dependent Viscosity and Thermal Conductivity past a Permeable Wedge with Uniform Surface Heat Flux, Int. J. Therm. Sci., Vol. 39, pp. 635-644.

Hossain, M. A., Kabir, S. and Rees, D. A. S. (2002): Natural Convection of Fluid with Variable Viscosity from a Heated Vertical wavy surface, Z. Angew. Math. Phys., Vol. 53, pp. 48-52.

Kays, W. M. (1966): Convective Heat and Mass Transfer, McGraw-Hill, New York, pp. 362.

Keller, H. B. (1978): Numerical Methods in Boundary Layer Theory, Annual Rev. Fluid Mechanics, Vol. 10, pp. 417-433. http://dx.doi.org /10.1146/ annurev.fl.10.010178.002221

Mehta, K. N. and Sood, S. (1992): Transient Free Convection Flow with Temperature Dependent Viscosity in a Fluid Saturated Porous Media, Int. J. Engrg. Sci., Vol. 30, pp. 1083-1087.

Molla, M. M., Hossain, M. A. and Yao, L. S. (2004): Natural Convection Flow along a Vertical Wavy Surface with Uniform Surface Temperature in Presence of Heat Generation/Absorption, Int. J. Thermal. Sciences, Vol. 43, pp. 157-163. http://dx.doi.org/10.1016/j.ijthermalsci.2003.04.001

Molla, M. M., Hossain, M. A. and Gorla, R. R. S. (2009): Natural Convection Laminar Flow with Temperature Dependent Viscosity and Thermal Conductivity along a Vertical Wavy Surface, Int. J. of Fluid Mech. Research, Vol. 36, pp. 272-288.

Palani, G. and Kim, K. Y. (2010): Numerical Study on a Vertical Plate with Variable Viscosity and Thermal Conductivity, Arch Appl. Mech., Vol. 80, pp. 711-725.

Parveen, N. and Alim, M. A. (2011): Joule Heating Effect on Magnetohydrodynamic Natural Convection Flow along a Vertical Wavy Surface with Viscosity Dependent on Temperature, International Journal of Energy \& Technology, Vol. 3 (1), pp. 1-11.

Parveen, N. and Alim, M. A. (2012): MHD Natural Convection Flow along a Vertical Wavy Surface in Presence of Heat Generation/Absorption with Viscosity Dependent on Temperature, Journal of Mechanical Engineering, Vol. ME 42 (1), pp. 47-55.

Rees, D. A. S and Pop, I. (1995): Free Convection Induced by a Vertical Wavy Surface with Uniform Heat Flux in a Porous Medium, J. Heat Transfer, Vol. 117, pp. 545-550.

Yao, L. S. (1983): Natural Convection along a Vertical Wavy Surface, ASME J. Heat Transfer, Vol. 105, pp. 465-468.

Yao, L. S. (2006): Natural Convection along a Vertical Complex Wavy Surface, Int. J. Heat and Mass Transfer, Vol. 49, pp. 281-286. 